\title{
Spectroscopy of OSSO and Other Sulfur Compounds Thought to be Present in the Venus Atmosphere
}

\author{
Benjamin N. Frandsen, Sara Farahani, Emil Vogt, Joseph R. Lane, and Henrik G. Kjaergaard* \\ Cite This: https://dx.doi.org/10.1021/acs.jpca.0c04388 \\ Read Online
}

ABSTRACT: The spectroscopy of cis-OSSO and trans-OSSO is explored and put into the context of the Venusian atmosphere, along with other sulfur compounds potentially present there, namely, $\mathrm{S}_{2} \mathrm{O}$, $\mathrm{C}_{1}-\mathrm{S}_{2} \mathrm{O}_{2}$, trigonal- $\mathrm{S}_{2} \mathrm{O}_{2}$, and $\mathrm{S}_{3}$. UV-vis spectra were calculated using the nuclear ensemble approach. The calculated OSSO spectra are shown to match well with the 320-400 nm near-UV absorption previously measured on Venus, and we discuss the challenges of assigning OSSO as the Venusian near-UV absorber. The largest source of uncertainty is getting accurate concentrations of sulfur monoxide $\left({ }^{3} \mathrm{SO}\right)$ in the upper cloud layer of Venus $(60-70 \mathrm{~km}$ altitude) since the ${ }^{3} \mathrm{SO}$ self-reaction is what causes cis- and transOSSO to form. Additionally, we employed the matrix-isolation

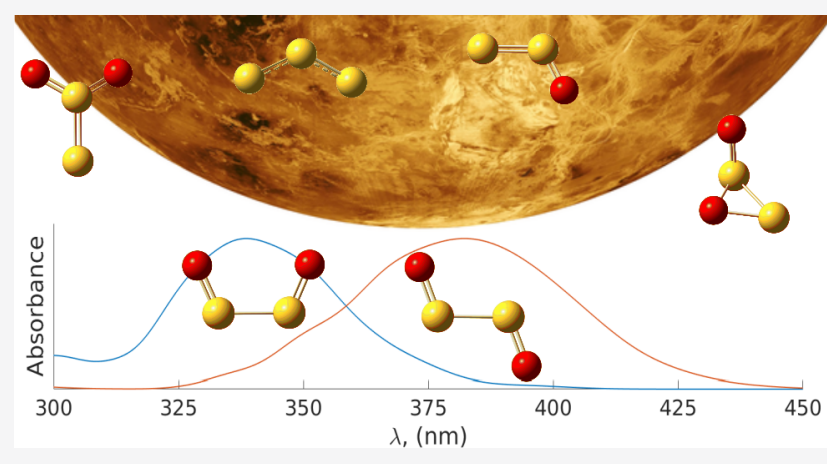
technique to trap OSSO formed by microwave discharging a gas mixture of argon and $\mathrm{SO}_{2}$ and then depositing the mixture onto a cold window $(6-12 \mathrm{~K})$. Anharmonic vibrational transition frequencies and intensities were calculated at the coupled cluster level to corroborate the matrix-isolation FTIR spectra. The computationally calculated UV-vis and experimentally recorded IR spectra presented in this work aid future attempts at detecting these sulfur compounds in the Venusian atmosphere.

\section{INTRODUCTION}

On Venus, $\mathrm{SO}_{2}$ is the main $\mathrm{UV}$ absorber at wavelengths from 200 to $320 \mathrm{~nm}^{1-3}$ However, at wavelengths longer than 320 $\mathrm{nm}$, something other than $\mathrm{SO}_{2}$ is absorbing, which has not yet been assigned with certainty. ${ }^{4-6}$ There have been several proposed candidates to match the absorption, including $\mathrm{S}_{2} \mathrm{O}$, sulfur allotropes $\left(\mathrm{S}_{3}\right.$ and $\left.\mathrm{S}_{4}\right), \mathrm{SCl}_{2}$, croconic acid, $\mathrm{FeCl}_{3}$ in aerosols, and even biomolecules formed by living organisms and recently cis-OSSO and trans-OSSO. ${ }^{6-14}$ The two OSSO isomers must exist on Venus to some degree because sulfur monoxide $\left({ }^{3} \mathrm{SO}\right.$, ground state is a triplet $)$ has been observed on Venus in several ways, ${ }^{15-19}$ and it has previously been found that ${ }^{3} \mathrm{SO}$ self-reacts with no barrier to form either cis-OSSO or trans-OSSO. $^{12}$

$$
{ }^{3} \mathrm{SO}+{ }^{3} \mathrm{SO} \rightarrow \text { OSSO }
$$

Additionally, the calculation of the vertical electronic transitions of the two OSSO isomers has unravelled where in the UV-vis spectrum they will absorb, though the actual spectral shape cannot be confidently obtained from a single excitation from the equilibrium geometries. ${ }^{12}$ At the altitudes where the unknown UV absorber is mainly located $(60-70 \mathrm{~km}$ altitude), the ${ }^{3} \mathrm{SO}$ concentration is hard to determine. ${ }^{5,20,21}$ Recently, Marcq et al. have estimated that the ${ }^{3} \mathrm{SO}$ concentration is $10 \%$ of the $\mathrm{SO}_{2}$ concentration based on Hubble telescope measurements that constrain the ${ }^{3} \mathrm{SO}$ concentration at $74-81 \mathrm{~km}$ altitudes. ${ }^{19,22}$ Earlier measure- ments done by the International UV Explorer arrive at ${ }^{3} \mathrm{SO}$ concentrations of $12-20 \mathrm{ppb}$ below $70 \mathrm{~km} .{ }^{15,16}$ However, there is expressed skepticism of these results based on photochemical modeling. ${ }^{23}$ Consensus on whether or not OSSO can be assigned to the near-UV absorption on Venus has not been established yet, and although it remains a promising candidate it depends largely on the ${ }^{3} \mathrm{SO}$ concentration at $60-70 \mathrm{~km}$ altitude. ${ }^{6,12,22-24}$

The potential near-UV absorber needs to absorb in the right region and be present in sufficient concentration. Recently, Pérez-Hoyos et al. ${ }^{6}$ concluded that $\mathrm{S}_{2} \mathrm{O}$ and the two OSSO isomers currently "provide the best agreement" with the nearUV absorption on Venus. Pérez-Hoyos et al. ${ }^{6}$ used simulated OSSO spectra based on calculated vertical electronic transition energies and oscillator strengths and spectra of the higher energy conformer of the cyc- $\mathrm{S}_{2} \mathrm{O}$ (vide infra). ${ }^{12,25}$ This illustrates the need for high-quality absorption spectra of these sulfur oxides. Recently, we showed that for a series of sulfur compounds $\left(\mathrm{SO}_{2}, \mathrm{SO}_{3}, \mathrm{H}_{2} \mathrm{~S}\right.$, OCS, and $\left.\mathrm{CS}_{2}\right)$, the nuclear

Received: May 15, 2020

Revised: August 10, 2020

Published: August 11, 2020 
ensemble approach, developed by Barbatti et al., can be used to calculate the full electronic spectra, including the bandwidths, in good agreement with experiments. ${ }^{26-31}$ Here we use this relatively new finding to calculate high-quality UV-vis spectra for cis- and trans-OSSO and compare them to the unknown near-UV absorber on Venus. Additionally, we calculate the $\mathrm{UV}$-vis spectra of $\mathrm{S}_{3}$ and two $\mathrm{S}_{2} \mathrm{O}$ isomers, as these sulfur compounds have also been suggested as potentially matching the unknown Venus absorber. ${ }^{6,8,10}$ Finally, for completeness, we calculate the spectra of two other $\mathrm{S}_{2} \mathrm{O}_{2}$ isomers, $\mathrm{C}_{1}-\mathrm{S}_{2} \mathrm{O}_{2}$ and trigonal- $\mathrm{S}_{2} \mathrm{O}_{2}$, for which no UV-vis spectral data are available in the literature. These isomers are predicted to be stable compounds and may be formed from the complex sulfur chemistry in the Venusian atmosphere, and knowing their UV-vis spectral profiles could be an important improvement for future photochemical modeling studies on Venus. ${ }^{12,23,32}$ Where possible, the calculated spectra are compared with experimental data available. ${ }^{25,33-38}$

It is difficult to get a good estimate of the OSSO concentration with a high degree of confidence due to a lack of accurate estimates of the OSSO precursor concentration, ${ }^{3} \mathrm{SO}$, and the rate constant of OSSO formation, in the altitude range of the Venusian near-UV absorption $(60-70 \mathrm{~km}$ altitude). ${ }^{5,39}$ Previously, the rate constant of OSSO formation was calculated in the high-pressure limit, based on collision theory with a collision diameter estimated from a potential energy surface scan. ${ }^{12}$ Here, we improve the level of kinetics theory by using variable reaction coordinate transition state theory (VRC-TST) to calculate the high-pressure rate constant. The advantage of this method is that we avoid having to choose the reactive collisional diameter of the ${ }^{3} \mathrm{SO}$ molecules based on a visual inspection of the potential energy surface. Instead, the rate constant is calculated with microcanonical variational transition state theory $(\mu \mathrm{VTST}) .^{40-42}$

Experimental observation of spectral signatures belonging to cis- and trans-OSSO is important to aid in the potential assignment of the OSSO isomers and other compounds predicted to exist in the Venusian atmosphere. Spectral assignment of vibrational transitions belonging to OSSO and other relevant compounds gives a fingerprint to look for in the infrared spectra from the Venusian atmosphere. A matrixisolation instrument was set up with an FTIR spectrometer in an attempt to detect IR signatures of the OSSO isomers. To produce OSSO, the system was set up so $\mathrm{SO}_{2}$ could be subjected to a microwave discharge, which would break the bonds in $\mathrm{SO}_{2}$ and form new sulfur oxides as products. Previously, discharge methods have been shown to produce ${ }^{3} \mathrm{SO}, \mathrm{S}_{2} \mathrm{O}$, and cis-OSSO. ${ }^{43-45}$

Computational Details. Electronic absorption spectra calculated in this work follow a similar approach to that recently shown to accurately reproduce electronic absorption spectra of small sulfur-containing molecules. ${ }^{31}$ For the UV-vis spectral simulation, the molecules investigated, cis-OSSO, trans-OSSO, $\mathrm{C}_{1}-\mathrm{S}_{2} \mathrm{O}_{2}$, trigonal- $\mathrm{S}_{2} \mathrm{O}_{2}, \mathrm{~S}_{3}, \mathrm{~S}_{2} \mathrm{O}$, and cyc- $\mathrm{S}_{2} \mathrm{O}$, were first structurally optimized, and normal modes were calculated using $\operatorname{CCSD}(\mathrm{T})$ with the aug-cc-pV $(\mathrm{T}+\mathrm{d}) \mathrm{Z}$ basis set with the Molpro 2012 program. ${ }^{46,47}$ To calculate the UVvis spectra, the Newton-X program was used, which employs the nuclear ensemble approximation. ${ }^{27,28}$ Newton-X was used to generate a nuclear ensemble using a Wigner distribution, ${ }^{48}$ with the normal coordinates obtained from the $\operatorname{CCSD}(\mathrm{T}) /$ aug-cc-pV $(\mathrm{T}+\mathrm{d}) \mathrm{Z}$ frequency calculations. The size of each nuclear ensemble is 2000 geometries, which was found appropriate for the benchmark molecules investigated by Farahani et al. $\left(\mathrm{SO}_{2}, \mathrm{SO}_{3}, \mathrm{H}_{2} \mathrm{~S}\right.$, OCS, and $\left.\mathrm{CS}_{2}\right)$, and further increasing the size has a diminishing return on improving spectral quality. ${ }^{31}$ As shorthand for describing the combination of $\mathrm{ab}$ initio methods employed for the geometry optimizations and electronic excitation calculations, we write $\operatorname{CCSD}(\mathrm{T}) / /$ EOM-CCSD/aug-cc-pV $(T+d) Z$, where $\operatorname{CCSD}(T)$ is the geometry optimization method and EOM-CCSD the electronic excitation calculation method, with both calculations using the aug-cc-pV(T+d)Z basis set. Vertical excitation energies and oscillator strengths for the first five excited states were calculated for each geometric structure in the ensemble using the EOM-CCSD/aug-cc-pV(T+d)Z method in Gaussian $09 .{ }^{49}$ Each individual vertical excitation was convoluted using a $\delta=0.1 \mathrm{eV}$ full width at half-maximum (fwhm) Gaussian function, as recommended. ${ }^{31}$ In the Supporting Information we compare the approach used here with the approach used in the previous work and find that the two approaches produce essentially equivalent data for the calculated $\mathrm{SO}_{2}$ spectrum. ${ }^{31}$

To get accurate vibrational transition frequencies and intensities, vibrational second-order perturbation theory (VPT2) was used. VPT2 is implemented in the CFOUR program and includes anharmonicity in the calculation of transition frequencies and intensities. ${ }^{50-56}$ For the VPT2 calculations, the molecules, cis-OSSO, trans-OSSO, $\mathrm{C}_{1}-\mathrm{S}_{2} \mathrm{O}_{2}$, and trigonal- $\mathrm{S}_{2} \mathrm{O}_{2}$, were geometry optimized in the CFOUR program before running the VPT2 calculations themselves. Both the geometry optimizations and VPT2 calculations were done at the $\operatorname{CCSD}(\mathrm{T}) /$ aug-cc-pV $(\mathrm{T}+\mathrm{d}) \mathrm{Z}$ level of theory. For both OSSO isomers, we also performed full-dimensional (6-D) local mode (LM) calculations, including Eckart axis-embedding, with an in-house code (see the Supporting Information for a detailed description). ${ }^{57-59}$ The single points used for the LM calculations were computed with the Molpro 2012 program, ${ }^{46}$ also at the $\operatorname{CCSD}(\mathrm{T}) /$ aug-cc-pV $(\mathrm{T}+\mathrm{d}) \mathrm{Z}$ level of theory.

Variable reaction coordinate transition state theory (VRCTST) was employed to calculate microcanonical variational transition state theory ( $\mu$ VTST) rate constants for the ${ }^{3} \mathrm{SO}+$ ${ }^{3} \mathrm{SO}$ reaction to form cis-OSSO and trans-OSSO. It has been shown that using this method provides results in good agreement with experiments for association/dissociation reactions. ${ }^{40,41}$ The calculations of VRC-TST rate constants were carried out using the Polyrate17 program which was combined with Gaussrate version 17-B. ${ }^{42,60}$ The M06-L functional was used for this part with the jun-cc-pV(D+d)Z basis set in the Gaussian 09 program. ${ }^{49}$ The "jun" basis set prefix was preferred over the "aug" basis set prefix, as it alleviated some convergence issues encountered for the larger ("aug") basis set due to linear dependencies. ${ }^{61}$ The program procedure involves a Monte Carlo sampling of the potential energy surface, and to avoid discontinuities and/or convergence problems in the Gaussian 09 program, the calculations were unrestricted and the following keywords were used: guess $=\operatorname{mix}, \mathrm{scf}=\mathrm{xqc}$, and geom $=$ nocrowd.

\section{EXPERIMENTAL SECTION}

The matrix-isolation technique was employed to isolate molecules and probe them using infrared spectroscopy. Argon (Alphagaz $\geq 99.999 \%$ ) was used as a host gas with $\mathrm{SO}_{2}$ (Aldrich $\geq 99.98 \%$ ) mixed in. We used a closed cycle cryostat from Advanced Research Systems (CS202-SI-DMX-12-SS) with a DE-202SI cryocooler that has pressurized helium 
as its coolant. The matrix sample window was made of CsI, and the shrouds were made of $\mathrm{KBr}$. A thermostat (CryoCon 32) was connected to the setup with a silicon diode (LakeShore Cryotronics) and was used to monitor and control the temperature of the matrix sample window. We used an Edwards turbomolecular vacuum pump (EXT 750X) to keep a high vacuum in the experiments, and a pressure gauge (Balzers Compact Full Range Gauge, PKR 250) was connected to monitor the pressure inside the matrix chamber. To generate new sulfur compounds from $\mathrm{SO}_{2}$, such as ${ }^{3} \mathrm{SO}$ and the OSSO isomers, a microwave discharge was used on the $\mathrm{Ar}+\mathrm{SO}_{2}$ mixture during deposition to generate a plasma. This technique has been used previously to generate novel compounds in matrix-isolation spectroscopy. ${ }^{6-68}$ In the experiments, an adjustable $0-200 \mathrm{~W}, 2450 \mathrm{MHz}$ solid state microwave generator from Sairem (GMS200WSM) was used as a microwave source and was connected to an Evenson cavity (CAVITE EVENSON 01/01). This cavity was attached onto a quartz tube, which leads the gas mixture onto the cold sample window. The quartz tube had a $5.5 \mathrm{~mm}$ inner diameter, which narrows down to about half of that at the entry point to the matrix chamber. The generated plasma can cause the $\mathrm{SO}_{2}$ molecules to dissociate inside the tube due to the vacuum-UV radiation, the high temperature, and/or collisions with charged argon species and free electrons. The products are immediately trapped on the cold window after traversing the quartz tube. A commercial FTIR spectrometer (Bruker VERTEX 70) was used to carry out the spectral measurements on the cryogenic matrix. The spectral resolution was set to $0.2 \mathrm{~cm}^{-1}$, and each spectrum was recorded using 500 scans. We used an MCT detector, an MIR light source, and a $\mathrm{KBr}$ beamsplitter in these experiments. Background spectra were taken of the window after cooling it, before depositing any gases onto it. Temperatures for recording spectra were between 6 and 12 $\mathrm{K}$, while the window would be annealed to temperatures between 20 and $30 \mathrm{~K}$ between spectrum recordings, which allowed the atoms and molecules in the matrix to move around so reactions could occur. To anneal the matrix, the attached thermostat was set to the desired temperature for $10 \mathrm{~min}$ before the matrix was cooled back down to the temperature used when recording the spectra. After annealing was done, the system was allowed at least $5 \mathrm{~min}$ to thermally stabilize before recording a spectrum.

\section{RESULTS AND DISCUSSION}

Photochemistry of $\mathrm{SO}_{2}$ and ${ }^{3} \mathrm{SO}$ in a Venus Context. The mechanism for the formation of ${ }^{3} \mathrm{SO}$ is naturally quite important, as it is the precursor for OSSO. Direct photolysis of $\mathrm{SO}_{2}$ is considered to be the main source of ${ }^{3} \mathrm{SO}$ in the middle atmosphere of Venus. ${ }^{23,69-74}$ This direct photolysis happens with radiation at wavelengths shorter than $220 \mathrm{~nm} .^{75-77}$

$$
\mathrm{SO}_{2}+h \nu(<220 \mathrm{~nm}) \rightarrow \mathrm{SO}+\mathrm{O}
$$

$\mathrm{SO}_{2}$ dominates the UV spectrum of the Venusian atmosphere at wavelengths shorter than $320 \mathrm{~nm}$, and the excited states of $\mathrm{SO}_{2}$ are known to participate in a variety of reactions. ${ }^{73,78-86}$ Some of these reaction have been brought to attention previously in the literature and are said to be "worthwhile to consider" in a Venus context. ${ }^{87-90}$ Excitation by the first singlet band with a maximum near $280 \mathrm{~nm}$ is known to result in a significant portion of excited $\mathrm{SO}_{2}$ molecules.

$$
\mathrm{SO}_{2}+h \nu(220-340 \mathrm{~nm}) \rightarrow{ }^{1} \mathrm{SO}_{2}\left({ }^{1} \mathrm{~B}_{2} /{ }^{1} \mathrm{~A}_{2}\right)
$$

In this first excited state the molecule can self-react with ground state $\mathrm{SO}_{2}{ }^{80}$

$$
{ }^{1} \mathrm{SO}_{2}+\mathrm{SO}_{2} \rightarrow \mathrm{SO}+\mathrm{SO}_{3}
$$

From its excited singlet state, $\mathrm{SO}_{2}$ can also cross into its lowest energy triplet state $\left({ }^{3} \mathrm{~B}_{1}\right)$. Direct excitation to the triplet state is also possible with radiation at $340-400 \mathrm{~nm}$ wavelength, although the absorption cross section for this transition is orders of magnitude lower than for the first singlet band. ${ }^{91}$

$$
\mathrm{SO}_{2}+h \nu(340-400 \mathrm{~nm}) \rightarrow{ }^{3} \mathrm{SO}_{2}\left({ }^{3} \mathrm{~B}_{1}\right)
$$

The triplet state has a phosphorescence lifetime of $\sim 0.9 \mathrm{~ms}$ and is proposed to be involved in several interesting atmospheric reactions. ${ }^{75,77,84-87,92-95}$ The ${ }^{3} \mathrm{SO}_{2}$ molecule is known to react with carbon monoxide $(\mathrm{CO})$ and with ground state $\mathrm{SO}_{2} \cdot{ }^{92,96,97}$

$$
\begin{aligned}
& { }^{3} \mathrm{SO}_{2}+\mathrm{CO} \rightarrow{ }^{3} \mathrm{SO}+\mathrm{CO}_{2} \\
& { }^{3} \mathrm{SO}_{2}+\mathrm{SO}_{2} \rightarrow{ }^{3} \mathrm{SO}+\mathrm{SO}_{3}
\end{aligned}
$$

Both $\mathrm{CO}$ and $\mathrm{SO}_{2}$ are quite abundant in the Venusian atmosphere, and both of these reactions form ${ }^{3} \mathrm{SO}$. Notably, $\mathrm{SO}_{2}$ absorption at wavelengths shorter than $320 \mathrm{~nm}$ is most significant in the Venus UV spectrum at the altitudes where the unknown UV absorber is mainly present $(60-70 \mathrm{~km}$ altitude). ${ }^{5,6,73}$ In an effort to uncover the impact that these processes actually have on Venus, the photolytic production of ${ }^{3} \mathrm{SO}$ through the reactions $2,4,6$, and 7 was calculated and is shown in Figure 1. To calculate these production rates, the values of $\mathrm{SO}_{2}$ concentration, $\mathrm{CO}$ concentration, atmospheric number density, and photon flux on Venus from Zhang et al. were used. ${ }^{73}$ We calculated the ${ }^{3} \mathrm{SO}$ formation rate with steady-

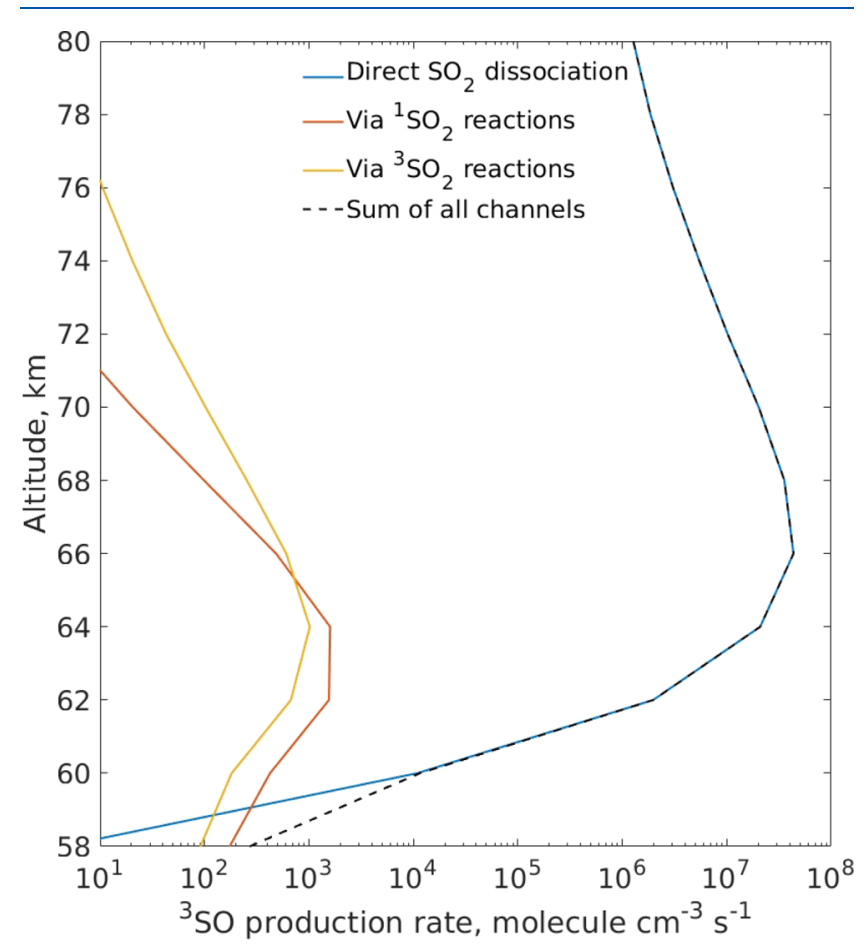

Figure 1. Photolytic production of ${ }^{3} \mathrm{SO}$ on Venus from $\mathrm{SO}_{2}$ through different channels, including direct photolytic cleavage of $\mathrm{SO}_{2}$ at wavelengths shorter than $220 \mathrm{~nm}$ and indirect pathways through reactions of either photoexcited ${ }^{1} \mathrm{SO}_{2}$ or ${ }^{3} \mathrm{SO}_{2}$; see the text for details. 

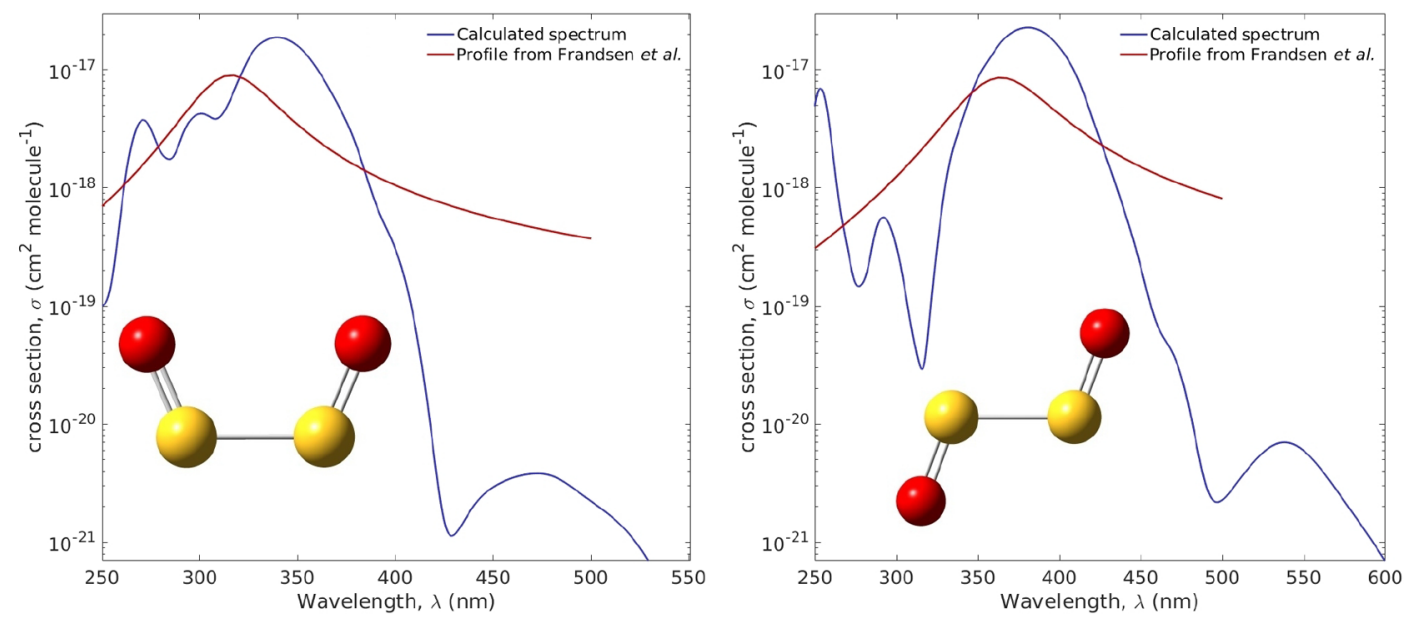

Figure 2. UV-vis spectrum of cis-OSSO (left) and trans-OSSO (right) with the single vertical excitation profile calculated at the $\mathrm{CC} 3 /$ aug-cc-pV(T $+\mathrm{d}) \mathrm{Z}$ level based on a MRCI/cc-pV(T+d) Z optimized geometry by Frandsen et al. ${ }^{12}$ (red) and the new calculated spectrum using the nuclear ensemble approach calculated at the $\operatorname{CCSD}(\mathrm{T}) / / \mathrm{EOM}-\mathrm{CCSD} / \mathrm{aug}-\mathrm{cc}-\mathrm{pV}(\mathrm{T}+\mathrm{d}) \mathrm{Z}$ level of theory (blue). See the Supporting Information for a linear $y$-axis version of this figure.

state approximations for both ${ }^{1} \mathrm{SO}_{2}$ and ${ }^{3} \mathrm{SO}_{2}$; see the Supporting Information for further details. The results in Figure 1 show that the direct photolysis of $\mathrm{SO}_{2}$ to form ${ }^{3} \mathrm{SO}$ dominates at almost all altitudes, compared to the indirect pathways through ${ }^{1} \mathrm{SO}_{2}$ and ${ }^{3} \mathrm{SO}_{2}$. This confirms that indirect pathways exceed the direct $\mathrm{SO}_{2}$ photolysis only at the lower boundary of $58 \mathrm{~km}$ altitude. However, these results indicate that $\mathrm{SO}_{2}$ could still do excited state chemistry, especially close to the lower boundary, and it should possibly be taken into account in future work on the Venus atmosphere. . $^{23,69-74}$ Identification of potentially important processes is needed to improve the Venus atmosphere models. ${ }^{98,99}$ Recently, it was suggested that excited state $\mathrm{SO}_{2}$ can abstract hydrogen atoms from water and alkanes, and further studies have suggested that $\mathrm{SO}_{2}$ can coat the interface of water-based aerosols, which potentially impacts its chemistry and photochemistry. ${ }^{85,86,100,101}$ It shows that there might be more to the photochemistry of $\mathrm{SO}_{2}$ than what is currently accounted for. Given how rich the Venusian atmosphere is in aerosols, it is probable that $\mathrm{SO}_{2}$ chemistry at the aerosol interface plays an important role.

The rate constant for OSSO formation from the ${ }^{3} \mathrm{SO}$ selfreaction was calculated in previous work using an experimental low-pressure rate constant from Herron and Huie and an estimated high-pressure (collision limit) rate constant. ${ }^{102}$ These were combined in a Troe scheme to calculate the rate constant over the Venusian middle atmosphere $(58-112 \mathrm{~km}$ altitude). ${ }^{12}$ In this work, the high-pressure rate constant is calculated using microcanonical variational transition state theory $(\mu \mathrm{VTST})$. It is important to take spin statistics into account for the reaction, since it is two triplet state molecules reacting to form a single molecule. Only 1 in 9 random ${ }^{3} \mathrm{SO}+$ ${ }^{3} \mathrm{SO}$ collisions follow a singlet potential energy surface (PES) while 3 in 9 follow a triplet PES and finally 5 in 9 a quintet PES. ${ }^{103}$ In the previous work, both the singlet and triplet PES were assumed to result in OSSO formation, and the estimated rate constant was $k_{\infty}=1.4 \times 10^{-11}$ molecule ${ }^{-1} \mathrm{~cm}^{3} \mathrm{~s}^{-1}$ at $T=$ $245 \mathrm{~K}$. The reasoning behind the triplet PES leading to OSSO formation is that a downhill product, a ${ }^{3}$ OSSO isomer, was identified with a geometry that resembles the transition state between the cis- and trans-OSSO isomers, which was suggested to convert to the singlet PES after its formation. ${ }^{12}$ In this work, using the same assumption that both singlet and triplet PES result in OSSO, we calculate a $k_{\infty, \mu \mathrm{VTST}}=1.7 \times 10^{-11}$ molecule $\mathrm{cm}^{3} \mathrm{~s}^{-1}$ at $T=245 \mathrm{~K}$. This different approach for calculating the rate constant is in very good agreement with the previous estimate, which helps validate the rate constant for OSSO formation. The $\mu$ VTST rate constant was found to have a small negative temperature dependence, which is consistent with a barrierless reaction; see the Supporting Information. Note that the $\mathrm{ab}$ initio calculations were only done on the singlet PES and were simply assumed to have the same end result following the triplet PES. This is a source of uncertainty in the high-pressure rate constant, and a lower estimate can be made by dividing the rate constant(s) above by a factor of 4, which assumes that the singlet PES pathway is the only one which forms OSSO; see the Supporting Information for details. Furthermore, the sampling procedure used to calculate the rate constant here does not distinguish between the two OSSO isomers, and thus the rate constant refers to the overall formation of OSSO. It can be safely assumed that the formation of OSSO via the singlet PES results in approximately equal amounts of cis- and trans-OSSO, based on the geometry of the cis/trans isomerization transition state identified in earlier work. ${ }^{12}$ It is however unknown if the triplet PES will result in more of one OSSO isomer than the other.

UV-Vis Spectra for cis-OSSO and trans-OSSO. Previously, the vertical electronic transition energy and oscillator strength were calculated at the $\mathrm{CC} 3 /$ aug-cc-pV $(\mathrm{T}+\mathrm{d}) \mathrm{Z}$ level of theory for the two lowest energy transitions of both OSSO isomers. However, the spectral shape of each transition was estimated using a simple Lorentzian function with a line width estimated from electronic transitions in other small sulfur species. These simulated spectra were sufficient to suggest OSSO as the unknown UV absober. ${ }^{6,12}$ Here, we use the nuclear ensemble approach within the Newton-X program to directly calculate the spectral shape and width of the UV-vis spectra. The new calculated spectra of cis-OSSO and trans-OSSO using the nuclear ensemble approach are shown in Figure 2. The simulated spectra reported by Frandsen et al. are also shown for comparison. ${ }^{12}$ An interesting result is that for cis- and trans- 
OSSO, the peak maxima, which are located at 339 and $381 \mathrm{~nm}$, respectively, are both red-shifted compared to the CCSD calculation in earlier work. ${ }^{12}$ Note that the difference between CC3 and CCSD vertical excitation energies was explored by Frandsen et al. and was found to be small, $<0.04 \mathrm{eV}$, which corresponds to a few nanometer shift for the two OSSO isomers. ${ }^{12}$ There are other more significant factors that cause this shift. First, the geometry of the OSSO isomers was optimized at the MRCI/cc-pV(T+d)Z level of theory in earlier work, while in this work the geometry was optimized at the $\operatorname{CCSD}(\mathrm{T}) /$ aug-cc-pV $(\mathrm{T}+\mathrm{d}) \mathrm{Z}$ level. Second, as part of this work we have tried manually displacing the molecular geometry of cis- and trans-OSSO along each normal mode and found that most displacements away from the equilibrium geometry cause a red shift of the dominant electronic transition. Thus, when we use the nuclear ensemble approach, which generates molecular geometries randomly displaced along the normal coordinates, the peak will on average shift toward the red. The vertical excitation energy from the equilibrium geometry was calculated using the exact same ab initio method for calculating the electronic transitions as was employed in the nuclear ensemble approach in this work. We find that the second vertical transition for cis-OSSO is at 333 $\mathrm{nm}$ and for trans-OSSO at $374 \mathrm{~nm}$, which means the sampling approach alone caused a red shift of 0.08 and $0.05 \mathrm{eV}$ for the second electronic transition in cis- and trans-OSSO, respectively. The new calculated spectra have additional features that arise from including more electronic transitions in the calculations. The nuclear ensemble approach with the Gaussian line broadening for the individual transitions decays much faster and more realistically than the single broad Lorentzian that Frandsen et al. used. ${ }^{12}$

Recently, Wu et al. assigned cis- and trans-OSSO in a matrixisolation experiment. ${ }^{104}$ They assigned a transition at $517 \mathrm{~nm}$ to the first electronic transition in trans-OSSO in an $\mathrm{N}_{2}$ matrix at $12 \mathrm{~K}$. Additional features at 375 and $390 \mathrm{~nm}$ were assigned to the second electronic transition in cis- and trans-OSSO, respectively. ${ }^{104}$ The peak maxima in our calculated spectra for the first electronic transitions in cis- and trans-OSSO are at 473 and $538 \mathrm{~nm}$, respectively, and the second transitions are at 339 and $381 \mathrm{~nm}$. Peak maxima placements appear to be somewhat in agreement with the $\mathrm{Wu}$ et al. assignments, with the biggest difference being between their assigned cis-OSSO peak maximum and our calculated electronic transition, 375 and $339 \mathrm{~nm}$, respectively. ${ }^{104}$ The $375 \mathrm{~nm}$ band that they assign to cis-OSSO is broad and potentially includes two overlapping bands, with the cis-OSSO signal belonging to the shorter wavelength part of the bands at $\sim 360 \mathrm{~nm}$. It can be seen in their spectra that the second trans-OSSO transition is around a factor of 3-4 times more intense than the first transition. ${ }^{104}$ In this work, the corresponding calculated difference in intensity exceeds a factor of 1000, which is in disagreement with what $\mathrm{Wu}$ et al. assigned experimentally. ${ }^{104}$ Additionally, they calculated a zero oscillator strength for the first vertical excitation in trans-OSSO with their TD-DFT calculations, which was also found in previous work using coupled-cluster calculations. ${ }^{12}$ The calculated spectra here show the first band with a nonzero cross section as the sampling procedure generates nonequilibrium geometries that break the molecular symmetry. However, as expected based on the vertical excitation calculations, the cross section for the symmetryforbidden first transition in cis- and trans-OSSO is still orders of magntitude lower than for the second transition. We therefore suggest that the $517 \mathrm{~nm}$ band $\mathrm{Wu}$ et al. ${ }^{104}$ observed is unlikely to be caused by trans-OSSO.

The calculated UV-vis cross sections of cis- and trans-OSSO can be used to calculate the photolysis rate constant, $J$, which is important in trying to assign the enigmatic UV absorber on Venus. To do so, we set the Venusian altitude to $64 \mathrm{~km}$ altitude and the latitude to $0^{\circ}$ to be able to directly compare the values with the ones calculated in previous work. ${ }^{12} \mathrm{We}$ calculate $J$ values of $0.20 \mathrm{~s}^{-1}$ for cis-OSSO and $0.62 \mathrm{~s}^{-1}$ for trans-OSSO, in agreement with the earlier values of 0.16 and $0.39 \mathrm{~s}^{-1}$, respectively. ${ }^{12}$ This photolysis rate calculation includes the bands corresponding to the first transition in cis- and trans-OSSO, and in the interest of uncovering their impact on the overall OSSO photolysis rate, we calculate how much they contribute to the $J$ values at $64 \mathrm{~km}$ altitude. We find that these bands contribute less than $0.3 \%$ to the $J$ value, which is negligible. Note that the calculated OSSO spectra cut off at around $\sim 250 \mathrm{~nm}$, which means contributions from shorter wavelength photons are missed in the calculation of the $J$ values. This should mainly be a source of systematic error at high altitudes in the Venusian atmosphere (100-110 km), where most of the short-wavelength photon flux from the sun has not been filtered by the atmosphere.

The enigmatic Venusian UV absorber was investigated by both Haus et al. and Pérez-Hoyos et al. in an attempt to retrieve its UV spectrum. ${ }^{5,6}$ Their resulting spectral profile can be compared to our calculated OSSO spectra; see Figure 3. We
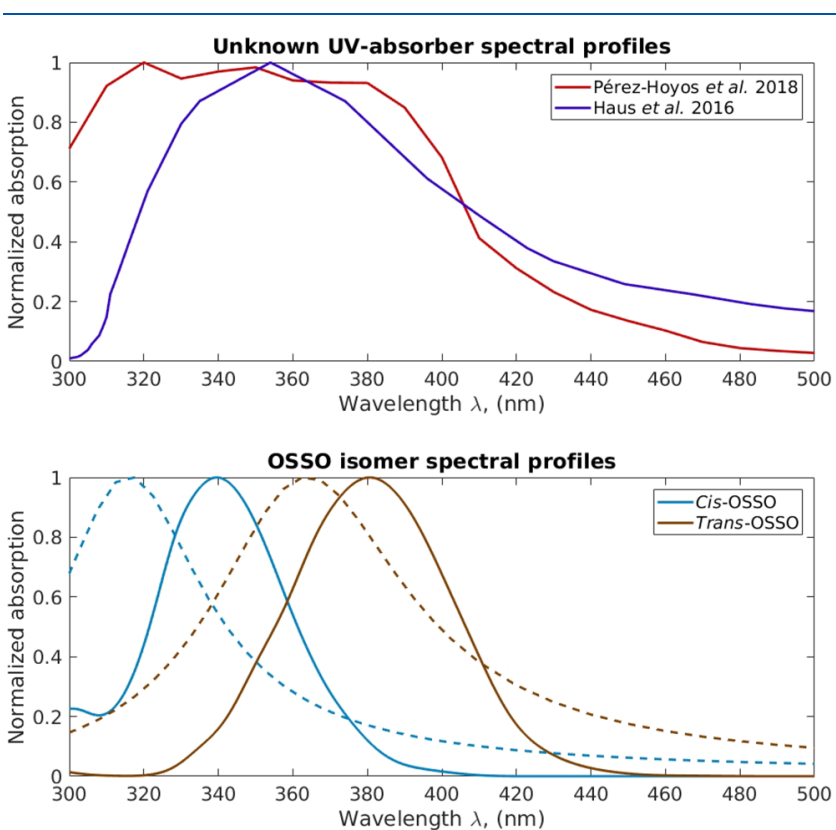

Figure 3. Retrieved spectral profile of the Venus near-UV absorber (top) and the calculated spectral profiles of the cis- and trans-OSSO isomers (bottom). The dashed lines for OSSO are the profiles from Frandsen et al. ${ }^{12}$ while the solid lines are from this work. These are the same profiles as in Figure 2, but here they are all normalized and shown on a linear scale.

note that the two studies appear to have significant differences at wavelengths $300-330$ and $420-500 \mathrm{~nm}$, while they seem to be in relatively good agreement between 330 and $420 \mathrm{~nm}$.,6 Thus, while we show the whole $300-500 \mathrm{~nm}$ spectral range, we wish to draw focus on the spectral match between OSSO and the retrieved UV profiles of the unknown UV absorber in the $330-420 \mathrm{~nm}$ range. A direct comparison of mixed spectral 
profiles of OSSO to the unknown UV absorber spectral profiles is made in Figure 4. The two mixed cis- and trans-OSSO

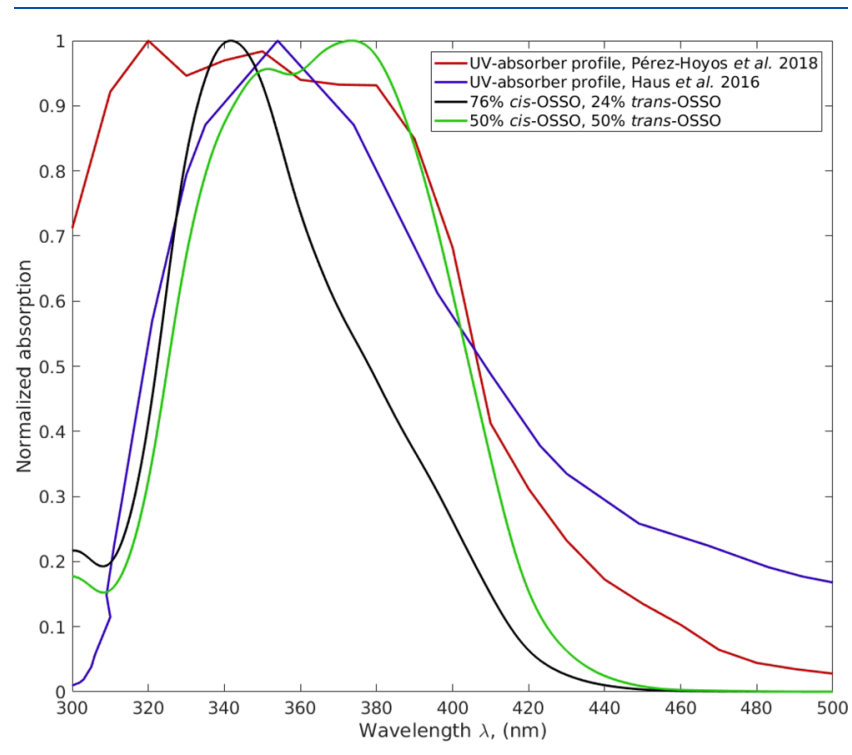

Figure 4. Retrieved spectral profiles of the unknown absorber on Venus compared to two different mixed cis- and trans-OSSO absorption profiles. The $76 \% / 24 \%$ OSSO profile (black) is based on the photolysis lifetime of the two OSSO isomers at $64 \mathrm{~km}$ altitude. The $50 \% / 50 \%$ OSSO profile (green) is based on the assumed isomer distribution upon formation from the ${ }^{3} \mathrm{SO}$ self-reaction.

profiles are based on our calculated spectra but with different population ratios. The population ratio in the black trace is calculated using the $J$ values for cis- and trans-OSSO; see the Supporting Information for details. The green trace profile is a straight $50 \% / 50 \%$ mix of the two OSSO isomers, which agrees with the observed population ratio in the matrix-isolation FTIR experiments discussed vide infra. The best spectral match between the unknown UV absorber profiles and our calculated OSSO spectra is clearly obtained with the 50\%/50\% mix of OSSO isomers. Based on the calculated $J$ values for the two OSSO isomers, and assuming photochemical control of the two OSSO isomer lifetimes, a $74 \% / 26 \%$ ratio should be found in the Venusian atmosphere. However, the real population distribution cannot easily be determined because it depends on much more than just the photolysis rate for each isomer, and several assumptions are made to arrive at the $74 \%$ /
$26 \%$ mix. For one, the ${ }^{3} \mathrm{SO}$ self-reaction is assumed to form cisand trans-OSSO in equal amounts, which at this point is not known. Furthermore, the quantum yield for photolytic cleavage of OSSO is assumed to be $\Phi=1$ at all wavelengths. Alternative routes to OSSO formation should also be considered, as these might result in more of one OSSO isomer than the other, such as the formation of trans-OSSO from the $\mathrm{C}_{1}-\mathrm{S}_{2} \mathrm{O}_{2}$ isomer; see Frandsen et al. for details. ${ }^{12} \mathrm{We}$ also assumed that destruction of the two OSSO isomers exclusively happens through photolytic cleavage based on their short photolysis lifetimes, but reactions could also be controlling the OSSO lifetimes if the quantum yield for OSSO photolysis is significantly lower than the assumed $\Phi=1$. Additionally, at lower altitudes where temperatures and pressures are higher and the actinic flux is lower, the two OSSO isomers might participate in chemistry since their photolytic lifetimes will be longer there, while they will encounter more molecules with a higher thermal energy. It is therefore not possible to arrive at an accurate population ratio of cis- and trans-OSSO until the discussed assumptions have been either validated or corrected. In a recent modeling study, the total OSSO abundance has been predicted to be 2 orders of magnitude lower than that needed to explain the near-UV absorption. This lower OSSO concentration originates primarily from a lower ${ }^{3} \mathrm{SO}$ concentration on which the OSSO concentration is very dependent. ${ }^{23}$

Matrix-Isolation FTIR Spectroscopy on OSSO. The matrix-isolation FTIR spectroscopy experiments carried out in this work gave rise to several peaks, which we assign to cis- and trans-OSSO based on full-dimensionality VPT2 and LM calculations; see Tables 1 and $2 .^{45,104,105} \mathrm{We}$ have also identified signals belonging to $\mathrm{SO}_{2},{ }^{3} \mathrm{SO}$, and $\mathrm{S}_{2} \mathrm{O}$, in agreement with the literature, which we discuss and show in the Supporting Information. ${ }^{25,104,106-109}$ We assign the $\nu_{2}$ mode in cis-OSSO to the peak at $1111.4 \mathrm{~cm}^{-1}$ and in transOSSO to the peak at $1105.7 \mathrm{~cm}^{-1}$; see Figure 5. The 1105.7 $\mathrm{cm}^{-1}$ transition matches the one $\mathrm{Wu}$ et al. identified at 1105.5 $\mathrm{cm}^{-1}$, which they also assigned to trans-OSSO. ${ }^{104} \mathrm{~A}$ weaker band is also seen in our experiments at $1105.1 \mathrm{~cm}^{-1}$, which is assigned to a site-splitting band from the main peak at 1105.7 $\mathrm{cm}^{-1}$ because these two appear with a constant intensity ratio. We note that $\mathrm{Wu}$ et al. did not assign two site split bands; this is likely due to the lower resolution $\left(0.5 \mathrm{~cm}^{-1}\right)$ that they used compared with our resolution of $0.2 \mathrm{~cm}^{-1}$. ${ }^{104}$ The transition at $1111.4 \mathrm{~cm}^{-1}$ seen here is close to the transition that $\mathrm{Wu}$ et al.

Table 1. Calculated and Experimental SO-Stretching Vibrational Transition Frequencies $\left(\mathrm{cm}^{-1}\right)$ and Intensities (in Parentheses in $\mathrm{km} / \mathrm{mol}$ ) in cis-OSSO

\begin{tabular}{|c|c|c|c|c|c|c|}
\hline \multicolumn{5}{|c|}{ calculated $\mathrm{ab}$ initio } & \multicolumn{2}{|c|}{ matrix IR spectroscopy $^{a}$} \\
\hline & $\mathrm{VPT}^{b}$ & 6-D LM ${ }^{c}$ & $\mathrm{Wu}$ et al. ${ }^{d}$ & Drumel et al. $^{e}$ & this work & Wu et al. \\
\hline$\nu_{2}$ & 1107 (168) & $1103(160)$ & $1122(738)$ & $1120(165)$ & 1111.4 & $1112.5(38)^{g}$ \\
\hline$\nu_{1}$ & $1160(51)$ & $1154(53)$ & $1173(125)$ & $1171(47)$ & $\sim 1159^{f}$ & $1159.3(100)^{g}$ \\
\hline $2 \nu_{2}$ & $2208(0.6)$ & $2204(0.7)$ & - & - & - & - \\
\hline$\nu_{1}+\nu_{2}$ & $2252(0.2)^{h}$ & $2246(4.0)$ & - & - & - & - \\
\hline $2 \nu_{1}$ & $2313(0.2)^{h}$ & $2305(0.8)$ & - & - & - & - \\
\hline
\end{tabular}

${ }^{a}$ The matrix-isolation experiments with argon as host gas. ${ }^{b} \mathrm{VPT} 2$ using the $\operatorname{CCSD}(\mathrm{T}) / \mathrm{AV}(\mathrm{T}+\mathrm{d}) \mathrm{Z}$ level of theory. ${ }^{c}$ Full-dimensionality local mode model with the $\operatorname{CCSD}(\mathrm{T}) / \mathrm{AV}(\mathrm{T}+\mathrm{d}) \mathrm{Z}$ level of theory; see the Supporting Information for details. ${ }^{d} \mathrm{CCSD}(\mathrm{T})$-F12b/VTZ-F12 calculated with anharmonicity. ${ }^{104}{ }^{e} \mathrm{VPT} 2$ using $\operatorname{CCSD}(\mathrm{T}) / \mathrm{cc}-\mathrm{pV}(\mathrm{Q}+\mathrm{d}) \mathrm{Z}$ with frozen-core approximation. ${ }^{45} f_{\text {Tentative assignment of a weak signal observed here; }}$ see the Supporting Information for details. ${ }^{g}$ Intensities were set relative to the most intense transition observed. These relative intensities have likely been switched by accident in the Wu et al. paper. ${ }^{104}{ }^{h}$ In the VPT2 calculations, the states associated with the $2 \nu_{1}$ and $\nu_{1}+\nu_{2}$ transitions are deperturbed and should be interpreted with caution. 
Table 2. Calculated and Experimental SO-Stretching Vibrational Transition Frequencies $\left(\mathrm{cm}^{-1}\right)$ and Intensities (in Parentheses in $\mathrm{km} / \mathrm{mol}$ ) in trans-OSSO

\begin{tabular}{|c|c|c|c|c|c|}
\hline & \multicolumn{3}{|c|}{ calculated $\mathrm{ab}$ initio } & \multicolumn{2}{|c|}{ matrix IR spectroscopy $^{a}$} \\
\hline & $\mathrm{VPT}^{b}$ & 6-D LM ${ }^{c}$ & Wu et al. ${ }^{d}$ & this work & Wu et al. \\
\hline$\nu_{2}$ & $1103(289)$ & $1097(264)$ & $1122(1552)$ & $1105.7,1105.1^{e}$ & 1105.5 \\
\hline$\nu_{1}$ & $1135(0)$ & $1125(0)$ & $1148(0)$ & - & - \\
\hline $2 \nu_{2}$ & $2199(0)$ & $2187(0)$ & - & - & $f$ \\
\hline$\nu_{1}+\nu_{2}$ & $2223(0.3)^{h}$ & $2208(6.8)$ & - & - & $2219.7^{f}$ \\
\hline $2 \nu_{1}$ & $2263(0)^{h}$ & $2244(0)$ & - & - & - \\
\hline
\end{tabular}

${ }^{a}$ The matrix-isolation experiments used argon as host gas. ${ }^{b} \mathrm{VPT} 2$ using the $\operatorname{CCSD}(\mathrm{T}) / \mathrm{AV}(\mathrm{T}+\mathrm{d}) \mathrm{Z}$ level of theory. ${ }^{c}$ Full-dimensionality local mode model with the $\operatorname{CCSD}(\mathrm{T}) / \mathrm{AV}(\mathrm{T}+\mathrm{d}) \mathrm{Z}$ level of theory, see the Supporting Information for details. ${ }^{d} \operatorname{CCSD}(\mathrm{T})$-F $12 \mathrm{~b} / \mathrm{VTZ}$-F12 calculated with anharmonicity. ${ }^{e}$ Site split band. ${ }^{f} \mathrm{Wu}$ et al. assign a weak signal observed at $2219.7 \mathrm{~cm}^{-1}$ to the first $\nu_{2}$ overtone in trans-OSSO. We suggest a better agreement with the $\nu_{1}+\nu_{2}$ combination band. ${ }^{h}$ In the VPT2 calculations, the states associated with the $2 \nu_{1}$ and $\nu_{1}+\nu_{2}$ transitions are deperturbed and should be interpreted with caution.
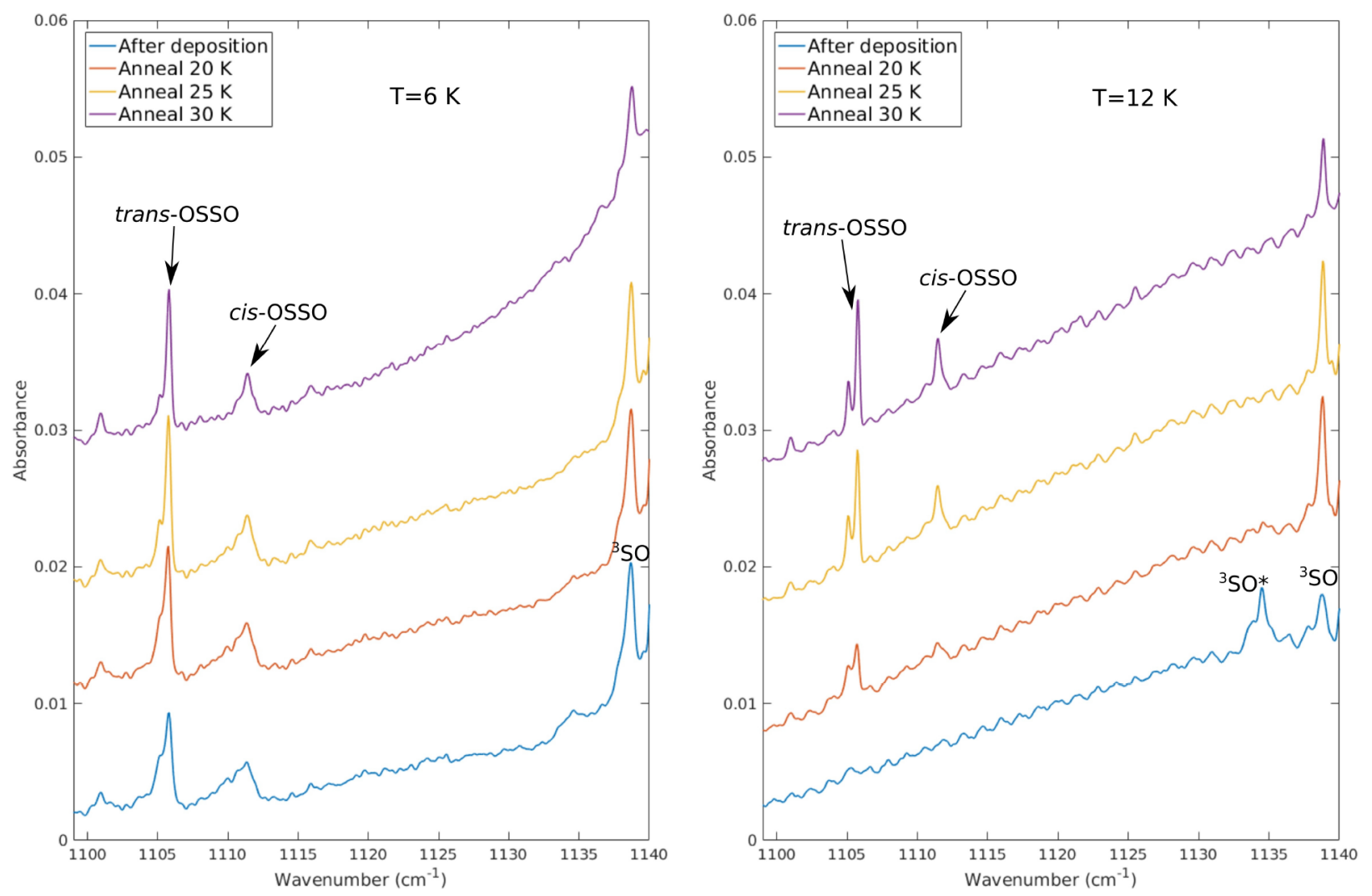

Figure 5. Matrix-isolation infrared spectroscopy of cis-OSSO and trans-OSSO formed after microwave discharge on $\mathrm{SO}_{2}$ in argon. Stable and metastable sites of ${ }^{3} \mathrm{SO}$ are assigned too. The spectra are offset for clarity. Left spectra: $\mathrm{SO}_{2}: \mathrm{Ar}$ ratio of 1:500, deposited and spectra recorded at $T=$ $12 \mathrm{~K}$. Deposition rate of $0.9 \mathrm{mmol} / \mathrm{h}$. Microwave discharge power set to $50 \mathrm{~W}$. Right spectra: $\mathrm{SO}_{2}: \mathrm{Ar}$ ratio of 1:2000, deposited and spectra recorded at $T=6 \mathrm{~K}$. Deposition rate of $1.1 \mathrm{mmol} / \mathrm{h}$. Microwave discharge power set to $60 \mathrm{~W}$.

observed at $1112.5 \mathrm{~cm}^{-1}$ and assigned to cis-OSSO, but the difference in the peak maximum is outside the spectral resolution in both our and their experiments. ${ }^{104}$ In Figure 5, the spectra with a 1:500 $\mathrm{SO}_{2}$ :Ar ratio (left spectra, $T=12 \mathrm{~K}$ ) show that the peaks assigned to cis-OSSO and trans-OSSO can be observed in the "after deposition" spectrum, while in the 1:2000 $\mathrm{SO}_{2}$ : Ar ratio experiments (right spectra, $T=6 \mathrm{~K}$ ) OSSO is observed only after annealing the matrix. We attribute this to more bimolecular chemistry happening in the plasma during deposition when the concentration of $\mathrm{SO}_{2}$ is higher, consistent with what has been observed in the literature. ${ }^{43,44}$ In the more dilute experiment, the OSSO signals grow in, which is attributed to bimolecular association of ${ }^{3} \mathrm{SO}$ happening in the matrix during annealing. An interesting observation is the signal at $1134.5 \mathrm{~cm}^{-1}$, which we assign to ${ }^{3} \mathrm{SO}$ in a metastable site, and to the best of our knowledge, this has not previously been reported; see Figure 5 (right spectra). It disappears after the first annealing to $20 \mathrm{~K}$, which coincides with the formation of OSSO. Additionally, the intensity of the stable ${ }^{3} \mathrm{SO}$ site increases as the metastable signal disappears, although this could also be attributed to free sulfur and oxygen atoms combining during annealing. The likely reason why this transition has not been assigned previously is because it is so unstable that the temperature of the matrix needs to be around $6 \mathrm{~K}$, which is lower than what previous studies used. $^{104,107,110,111}$ For cis-OSSO an additional feature was assigned to the $\nu_{1}$ mode by $\mathrm{Wu}$ et al. at $1159.3 \mathrm{~cm}^{-1}$. We observe a very weak signal at that same wavenumber in the 
1:2000 $\mathrm{SO}_{2}$ :Ar matrix-isolation experiment which grows in with annealing. We tentatively assign this to the $\nu_{1}$ mode in cisOSSO; see the Supporting Information for extended spectra that cover this region. ${ }^{104}$ In the experiment by $\mathrm{Wu}$ et al., they find that the cis-OSSO $\nu_{1}$ transition is three times more intense than the $\nu_{2}$ transition; however, this is perhaps a typo in their table. We find a calculated ratio of about 1:3 in favor of the $\nu_{2}$ transition from both the VPT2 and 6D LM calculations, which agrees with the work of Martin-Drumel et al. ${ }^{45}$ and also agrees with the fact that the signal we see at $\sim 1159 \mathrm{~cm}^{-1}$ is significantly weaker than the $\nu_{2}$ cis-OSSO signal at 1111.4 $\mathrm{cm}^{-1}$.

Integration of the $\nu_{2}$ peaks in both cis-OSSO and transOSSO in our experiments gave a 1:2 intensity ratio of cis:trans, which with our calculated intensity ratio (VPT2/LM) of 160/ 168 to $264 / 289 \mathrm{~km} / \mathrm{mol}$ for the two $\nu_{2}$ transitions in cis-OSSO and trans-OSSO, respectively, yields a $50 \% / 50 \%$ population ratio of cis/trans-OSSO formation in the matrix experiments.

$\mathrm{Wu}$ et al. assign the first overtone of the $\nu_{2}$ transition in trans-OSSO at $2219.7 \mathrm{~cm}^{-1}$. ${ }^{104}$ Based on our calculations, we find this peak in better agreement with the $\nu_{1}+\nu_{2}$ combination band, see Table 2 , as the $2 \nu_{2}$ transitions have zero intensity and the wavenumber match is better for the combination transition (a pure local mode and expected to carry the intensity in the overtone).

The possibility of the two $\mathrm{S}_{2} \mathrm{O}_{2}$ isomers, trigonal- $\mathrm{S}_{2} \mathrm{O}_{2}$ and $\mathrm{C}_{1}-\mathrm{S}_{2} \mathrm{O}_{2}$, being formed in the matrix was also considered, but no spectral features belonging to these two isomers were identified in this work. However, both of these $\mathrm{S}_{2} \mathrm{O}_{2}$ isomers could be formed in an atmospheric setting like on Venus, which is discussed in the next section. As part of our efforts to try and find these in the experiments, we calculated the vibrational frequencies and intensities of both trigonal- $\mathrm{S}_{2} \mathrm{O}_{2}$ and $\mathrm{C}_{1}-\mathrm{S}_{2} \mathrm{O}_{2}$ and have listed those results in the Supporting Information along with the full set of fundamental transition frequencies and intensities for cis- and trans-OSSO.

UV-Vis Spectra of Trigonal- $\mathrm{S}_{2} \mathrm{O}_{2}, \mathrm{C}_{1}-\mathrm{S}_{2} \mathrm{O}_{2}, \mathrm{~S}_{2} \mathrm{O}$, and $\mathrm{S}_{3}$. The two other $\mathrm{S}_{2} \mathrm{O}_{2}$ isomers, $\mathrm{C}_{1}-\mathrm{S}_{2} \mathrm{O}_{2}$ and trigonal- $\mathrm{S}_{2} \mathrm{O}_{2}$, are both relatively stable and could also be formed in the Venusian atmosphere. Previously, we limited our study of $\mathrm{S}_{2} \mathrm{O}_{2}$ formation on Venus to the ${ }^{3} \mathrm{SO}$ self-reaction. ${ }^{12}$ It is worth noting that other mechanisms of $\mathrm{S}_{2} \mathrm{O}_{2}$ formation exist, such as a sulfur atom reacting with $\mathrm{SO}_{2}$

$$
\mathrm{S}+\mathrm{SO}_{2} \rightarrow \mathrm{S}_{2} \mathrm{O}_{2}
$$

which has been studied in a combustion context where it leads to $\mathrm{SO}+\mathrm{SO}$ formation. ${ }^{32}$ At the lower temperatures of the Venus atmosphere $(58-112 \mathrm{~km}$ altitude), this reaction should terminate at the $\mathrm{S}_{2} \mathrm{O}_{2}$ intermediates. Free sulfur atoms are formed in the Venusian atmosphere through the UV photolysis of OCS. $^{73,112}$ Therefore, we calculated the UV-vis spectra of trigonal- $\mathrm{S}_{2} \mathrm{O}_{2}$ and $\mathrm{C}_{1}-\mathrm{S}_{2} \mathrm{O}_{2}$ using the nuclear ensemble approach; see Figure 6. These can be useful when modeling $\mathrm{S}_{2} \mathrm{O}_{2}$ photochemistry and can aid in assigning spectral features in future experiments or observations. On a logarithmic scale, the wavelengths longer than $325 \mathrm{~nm}$ catch the eye, but it should be noted that these have low cross sections, less than $10^{-19} \mathrm{~cm}^{2}$ molecule ${ }^{-1}$, and are unlikely to be responsible for the atmospheric Venus absorption from 320 to $400 \mathrm{~nm}$. It is mostly at wavelengths shorter than $300 \mathrm{~nm}$ where they absorb significantly, and in the case of Venus, such features are probably overshadowed by the much more abundant $\mathrm{SO}_{2}$ molecule's absorption features.

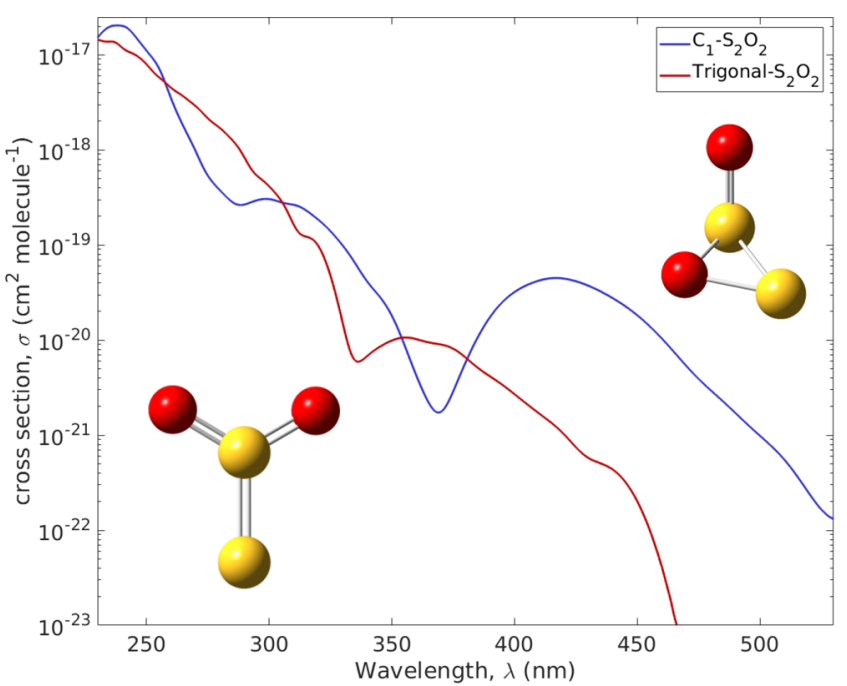

Figure 6. Calculated UV-vis spectrum of $\mathrm{C}_{1}-\mathrm{S}_{2} \mathrm{O}_{2}$ (blue) and trigonal- $\mathrm{S}_{2} \mathrm{O}_{2}$ (red). Calculated using the nuclear ensemble approach at the $\operatorname{CCSD}(\mathrm{T}) / / \mathrm{EOM}-\mathrm{CCSD} /$ aug-cc-pV $(\mathrm{T}+\mathrm{d}) \mathrm{Z}$ level of theory.

Pérez-Hoyos et al. concluded that OSSO was the overall best match for the enigmatic near-UV absorber on Venus, but it was actually "only" the second best spectral match. ${ }^{6}$ The best spectral match they reported was with a high-energy cyclic isomer of $\mathrm{S}_{2} \mathrm{O}$ (cyc- $\left.\mathrm{S}_{2} \mathrm{O}\right){ }^{25}$ The Gibbs energy difference calculated at the $\operatorname{CCSD}(\mathrm{T}) /$ aug-cc-pV $(\mathrm{T}+\mathrm{d}) \mathrm{Z}$ level between the cyc- $\mathrm{S}_{2} \mathrm{O}$ isomer and the normal $\mathrm{S}_{2} \mathrm{O}$ isomer ( $\mathrm{SSO}$, similar geometry to $\mathrm{SO}_{2}$ ) is $44 \mathrm{kcal} / \mathrm{mol}$. The normal $\mathrm{S}_{2} \mathrm{O}$ isomer was observed in our microwave discharge experiments (see the Supporting Information), while cyc- $\mathrm{S}_{2} \mathrm{O}$ was not observed, which is in agreement with the work of Tiemann et al. and the calculated relative stability. ${ }^{44}$ The cyc- $\mathrm{S}_{2} \mathrm{O}$ isomer was observed by Lo et al. only after irradiating matrix-isolated $\mathrm{S}_{2} \mathrm{O}$ in argon with a $308 \mathrm{~nm}$ laser. ${ }^{25}$ The cyclic isomer is either not formed during the discharge experiments or is so shortlived that it isomerizes to normal $\mathrm{S}_{2} \mathrm{O}$ before being isolated in the matrices. Our calculated $\mathrm{S}_{2} \mathrm{O}$ and cyc- $\mathrm{S}_{2} \mathrm{O}$ spectra are shown in Figure 7 with comparisons to the literature included. ${ }^{25,113}$ Note that multiplying the $\mathrm{SO}_{2} \mathrm{UV}$ cross section by a factor of 30 in the $260-340 \mathrm{~nm}$ region to obtain the spectral profile of $\mathrm{S}_{2} \mathrm{O}$ was recommended by Mills, ${ }^{113}$ based on earlier work by Jones, ${ }^{114}$ and is in surprisingly good agreement with our calculated spectrum. Based on the work of Cobos et al., ${ }^{37}$ there seems to be an overall good agreement in the literature with the normal $\mathrm{S}_{2} \mathrm{O}$ isomer spectrum. ${ }^{33,37,113,114}$ In the cyc- $\mathrm{S}_{2} \mathrm{O}$ spectrum the spectral feature at $530 \mathrm{~nm}$, which at peak maximum has about half the cross section of the $344 \mathrm{~nm}$ peak, is something that should be clearly seen in the UV-vis spectrum of Venus if cyc- $\mathrm{S}_{2} \mathrm{O}$ was actually the unknown UV absorber. It can therefore be discarded as a potential match to the unknown UV absorber. Another high-energy isomer of $\mathrm{S}_{2} \mathrm{O}$, the SOS isomer, has previously been studied computationally but was predicted to be extremely unstable and was therefore not included in this project. ${ }^{115}$

Spectral simulation of $S_{3}$ was also carried out in this work. The UV-vis spectral data on this molecule is limited, yet it was one of the early candidates suggested to match the unknown UV absorber on Venus along with $S_{4}$, and it is part of the Venusian atmospheric models. ${ }^{6,8,11,34-36,71-74,116}$ The calculated spectrum of $S_{3}$ (Figure 8) has a large absorption cross section in the region around $365 \mathrm{~nm}$ where the unknown near- 

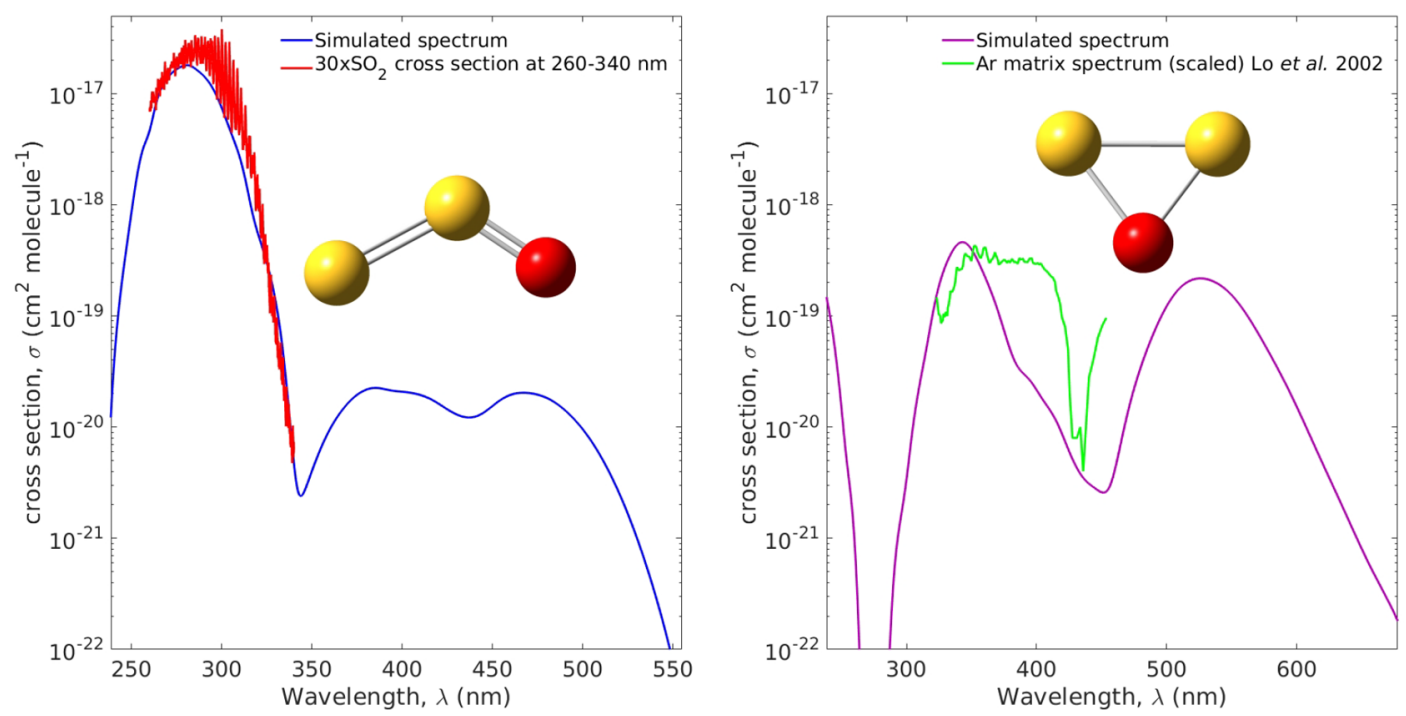

Figure 7. Calculated UV-vis spectra of $\mathrm{S}_{2} \mathrm{O}$ (left) and cyc- $\mathrm{S}_{2} \mathrm{O}$ (right) with the nuclear ensemble approach at the CCSD(T)//EOM-CCSD/augcc-pV(T+d)Z level of theory. The "30 times $\mathrm{SO}_{2}$ cross section" for the $\mathrm{S}_{2} \mathrm{O}$ spectral profile is based on the recommendation by Mills. ${ }^{113} \mathrm{The}$ cyc$\mathrm{S}_{2} \mathrm{O}$ Ar matrix spectrum is obtained from Pérez-Hoyos et al. who cite Lo et al. for the data. ${ }^{6,25}$ Note that since no absolute intensity was obtained in the cyc- $\mathrm{S}_{2} \mathrm{O}$ experimental spectrum by Lo et al. ${ }^{25}$ we have scaled it to match the maximum absorption of our calculated spectral profile. The $y$-axis is identical in both the left and the right spectrum.

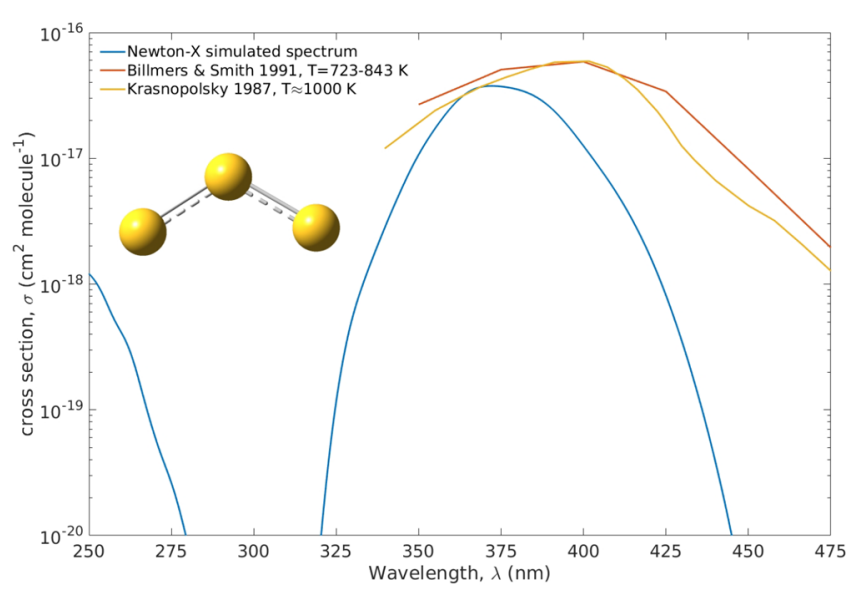

Figure 8. Calculated $\mathrm{S}_{3} \mathrm{UV}$-vis spectrum (blue) at the $\operatorname{CCSD}(\mathrm{T}) / /$ $\mathrm{EOM}-\mathrm{CCSD} /$ aug-cc-pV $(\mathrm{T}+\mathrm{d}) \mathrm{Z}$ level with the nuclear ensemble approach and experimental spectrum from Billmers and Smith ${ }^{36}$ (red) and Krasnopolsky (yellow). ${ }^{35}$

UV absorber on Venus mainly absorbs. However, as discussed earlier, a spectral match alone is not enough, but pure sulfur species or very low oxides might be interesting targets for future computational studies in a Venus context to aid modeling. ${ }^{6,8,73}$ The agreement between the experimental data sets from Krasnopolsky $(1987)^{35}$ and Billmers and Smith ${ }^{36}$ is good; however, our simulated spectrum does not have an excellent agreement with the experiments. It should be noted that the temperature is quite high in the two experimental data sets while no temperature effect has been included in the calculated spectrum $(T=0 \mathrm{~K})$; see the legend in Figure $8 .^{35,36}$ The temperature effect on UV-vis spectra can be quite noteworthy, resulting in both a clear shift of band maxima and changes in intensity. ${ }^{17}$

\section{CONCLUSION}

In this work, the photochemistry of $\mathrm{SO}_{2}$, which results in the formation of ${ }^{3} \mathrm{SO}$ and precedes OSSO formation, was discussed in the context of the Venusian middle atmosphere. The chemistry of $\mathrm{SO}_{2}$ 's first excited singlet state and triplet state was explored, and it was shown that the production of ${ }^{3} \mathrm{SO}$ via direct photodissociation of $\mathrm{SO}_{2}$ at wavelengths $<220$ $\mathrm{nm}$ exceeds the ${ }^{3} \mathrm{SO}$ production through the photochemistry of $\mathrm{SO}_{2}$ initiated by photon absorption at wavelengths $>220 \mathrm{~nm}$ at altitudes $60 \mathrm{~km}$ and up. This is despite the higher photon flux at longer wavelengths. We conclude that the excited state chemistry of $\mathrm{SO}_{2}$ is worth considering in future modeling studies on the Venusian atmosphere. The rate constant for OSSO formation from the ${ }^{3} \mathrm{SO}$ self-reaction was calculated using an improved level of kinetics theory compared to the previous work, and we found that it was in very good agreement with the rate constant calculated in the previous work.

The UV-vis spectra for the Venus relevant sulfur compounds, cis-OSSO, trans-OSSO, $\mathrm{C}_{1}-\mathrm{S}_{2} \mathrm{O}_{2}$, trigonal- $\mathrm{S}_{2} \mathrm{O}_{2}$, $\mathrm{S}_{2} \mathrm{O}$, cyc- $\mathrm{S}_{2} \mathrm{O}$, and $\mathrm{S}_{3}$, were calculated. These calculated spectra all have the potential to impact future Venusian atmospheric modeling as well as aid future experimental/observational studies in assigning these molecules. We have shown that a mix of cis- and trans-OSSO matches the enigmatic UV absorption on Venus quite well and thus OSSO remains a promising candidate to explain the unknown UV absorption on Venus, although further work is still needed. Vibrational transition frequencies and intensities were calculated for the $\mathrm{S}_{2} \mathrm{O}_{2}$ isomers, which assisted us in the assignment of cis-OSSO and trans-OSSO seen in the matrix-isolation FTIR spectroscopy experiments.

\section{ASSOCIATED CONTENT}

\section{SI Supporting Information}

The Supporting Information is available free of charge at https://pubs.acs.org/doi/10.1021/acs.jpca.0c04388.

Details on the UV-vis spectral calculations including validation of the method with $\mathrm{SO}_{2}$ as the test molecule; a linear $y$-axis version of Figure 2; details on how the relative OSSO isomer populations were obtained; a 
detailed description of the full-dimensionality local mode model used to calculate vibrational frequencies and intensities for the OSSO isomers; additional output from the calculations of vibrational transition frequencies and intensities; supplementary spectra from the matrix-isolation IR spectroscopy experiments; additional details on the rate constant for the ${ }^{3} \mathrm{SO}+{ }^{3} \mathrm{SO}$ reaction to form OSSO; details on how the formation rate of ${ }^{3} \mathrm{SO}$ from the photochemistry of $\mathrm{SO}_{2}$ was calculated (PDF)

\section{AUTHOR INFORMATION}

\section{Corresponding Author}

Henrik G. Kjaergaard - Department of Chemistry, University of Copenhagen, 2100 Copenhagen Ø, Denmark; 이이. ord. 0000-0002-7275-8297; Email: hgk@chem.ku.dk

\section{Authors}

Benjamin N. Frandsen - Department of Chemistry, University of Copenhagen, 2100 Copenhagen Ø, Denmark; Department of Chemistry, University of Colorado Boulder, Boulder, Colorado 80309, United States; (1) orcid.org/0000-0002-9211-3939

Sara Farahani - School of Science, University of Waikato, Hamilton 3240, New Zealand

Emil Vogt - Department of Chemistry, University of Copenhagen, 2100 Copenhagen Ø, Denmark; (1) orcid.org/ 0000-0003-3335-9813

Joseph R. Lane - School of Science, University of Waikato, Hamilton 3240, New Zealand; $\odot$ orcid.org/0000-0002-44742941

Complete contact information is available at: https://pubs.acs.org/10.1021/acs.jpca.0c04388

\section{Notes}

The authors declare no competing financial interest.

\section{ACKNOWLEDGMENTS}

We are grateful to professor Paul O. Wennberg and Professor Veronica Vaida for helpful discussions. H.G.K., E.V., and B.N.F. acknowledge the financial support from the Danish Center for Scientific Computing, University of Copenhagen and the Independent Research Fund, Denmark. S.F. and J.R.L are grateful to the Royal Society of New Zealand for a Marsden grant.

\section{REFERENCES}

(1) Pollack, J. B.; Ragent, B.; Boese, R.; Tomasko, M. G.; Blamont, J.; Knollenberg, R. G.; Esposito, L. W.; Stewart, A. I.; Travis, L. Nature of the Ultraviolet Absorber in the Venus Clouds: Inferences Based on Pioneer Venus Data. Science 1979, 205, 76-79.

(2) Pollack, J. B.; Toon, O. B.; Whitten, R. C.; Boese, R.; Ragent, B.; Tomasko, M.; Esposito, L.; Travis, L.; Wiedman, D. Distribution and source of the UV absorption in Venus' atmosphere. J. Geophys. Res. 1980, 85, 8141-8150.

(3) Ekonomov, A. P.; Moshkin, B. E.; Moroz, V. I.; Golovin, Y. M.; Gnedykh, V. I.; Grigorev, A. V. UV photometry at the Venera 13 and 14 landing probes. Cosmic Res. 1983, 21, 254-260.

(4) Ross, F. E. Photographs of Venus. Astrophys. J. 1928, 68, 57-92.

(5) Haus, R.; Kappel, D.; Tellmann, S.; Arnold, G.; Piccioni, G.; Drossart, P.; Häusler, B. Radiative energy balance of Venus based on improved models of the middle and lower atmosphere. Icarus 2016, 272, 178-205.

(6) Pérez-Hoyos, S.; Sánchez-Lavega, A.; García-Muñoz, A.; Irwin, P. G. J.; Peralta, J.; Holsclaw, G.; McClintock, W. M.; Sanz-Requena, J. F. Venus Upper Clouds and the UV Absorber From MESSENGER/
MASCS Observations. Journal of Geophysical Research: Planets 2018, $123,145-162$.

(7) Zasova, L.; Krasnopolsky, V.; Moroz, V. Vertical distribution of $\mathrm{SO}_{2}$ in upper cloud layer of Venus and Origin of U.V.-absorption. Adv. Space Res. 1981, 1, 13-16.

(8) Toon, O. B.; Turco, R. P.; Pollack, J. B. The ultraviolet absorber on Venus: Amorphous sulfur. Icarus 1982, 51, 358-373.

(9) Hartley, K. K.; Wolff, A. R.; Travis, L. D. Croconic acid: An absorber in the Venus clouds? Icarus 1989, 77, 382-390.

(10) Na, C. Y.; Esposito, L. W. Is Disulfur Monoxide a Second Absorber on Venus? Icarus 1997, 125, 364-368.

(11) Krasnopolsky, V. A. Chemical composition of Venus atmosphere and clouds: Some unsolved problems. Planet. Space Sci. 2006, 54, 1352-1359.

(12) Frandsen, B. N.; Wennberg, P. O.; Kjaergaard, H. G. Identification of OSSO as a near-UV absorber in the Venusian atmosphere. Geophys. Res. Lett. 2016, 43, 11146-11155.

(13) Krasnopolsky, V. A. On the iron chloride aerosol in the clouds of Venus. Icarus 2017, 286, 134-137.

(14) Limaye, S. S.; Mogul, R.; Smith, D. J.; Ansari, A. H.; Słowik, G. P.; Vaishampayan, P. Venus' Spectral Signatures and the Potential for Life in the Clouds. Astrobiology 2018, 18, 1181-1198.

(15) Na, C. Y.; Esposito, L. W.; Skinner, T. E. International ultraviolet explorer observation of Venus $\mathrm{SO}_{2}$ and SO. J. Geophys. Res. 1990, 95, 7485-7491.

(16) Na, C.; Esposito, L.; McClintock, W.; Barth, C. Sulfur Dioxide in the Atmosphere of Venus: II. Modeling Results. Icarus 1994, 112, 389-395.

(17) Sandor, B. J.; Clancy, R. T.; Moriarty-Schieven, G.; Mills, F. P. Sulfur chemistry in the Venus mesosphere from $\mathrm{SO}_{2}$ and $\mathrm{SO}$ microwave spectra. Icarus 2010, 208, 49-60.

(18) Belyaev, D. A.; Montmessin, F.; Bertaux, J.-L.; Mahieux, A.; Fedorova, A. A.; Korablev, O. I.; Marcq, E.; Yung, Y. L.; Zhang, X. Vertical profiling of $\mathrm{SO}_{2}$ and $\mathrm{SO}$ above Venus' clouds by SPICAV/ SOIR solar occultations. Icarus 2012, 217, 740-751. Advances in Venus Science.

(19) Jessup, K. L.; Marcq, E.; Mills, F.; Mahieux, A.; Limaye, S.; Wilson, C.; Allen, M.; Bertaux, J.-L.; Markiewicz, W.; Roman, T.; et al. Coordinated Hubble Space Telescope and Venus Express Observations of Venus' upper cloud deck. Icarus 2015, 258, 309-336.

(20) Haus, R.; Kappel, D.; Arnold, G. Radiative heating and cooling in the middle and lower atmosphere of Venus and responses to atmospheric and spectroscopic parameter variations. Planet. Space Sci. 2015, 117, 262-294.

(21) Lee, Y. J.; Yamazaki, A.; Imamura, T.; Yamada, M.; Watanabe, S.; Sato, T. M.; Ogohara, K.; Hashimoto, G. L.; Murakami, S. Scattering Properties of the Venusian Clouds Observed by the UV Imager on board Akatsuki. Astronomical Journal 2017, 154, 44.

(22) Marcq, E.; Jessup, K. L.; Baggio, L.; Encrenaz, T.; Lee, Y. J.; Montmessin, F.; Belyaev, D.; Korablev, O.; Bertaux, J.-L. Climatology of $\mathrm{SO}_{2}$ and UV absorber at Venus' cloud top from SPICAV-UV nadir dataset. Icarus 2020, 335, 113368.

(23) Krasnopolsky, V. A. Disulfur dioxide and its near-UV absorption in the photochemical model of Venus atmosphere. Icarus 2018, 299, 294-299.

(24) Marcq, E.; Baggio, L.; Lefévre, F.; Stolzenbach, A.; Montmessin, F.; Belyaev, D.; Korablev, O.; Bertaux, J.-L. Discovery of cloud top ozone on Venus. Icarus 2019, 319, 491-498.

(25) Lo, W.-J.; Wu, Y.-J.; Lee, Y.-P. Isomers of $\mathrm{S}_{2} \mathrm{O}$ : Infrared absorption spectra of cyclic $\mathrm{S}_{2} \mathrm{O}$ in solid Ar. J. Chem. Phys. 2002, 117, $6655-6661$.

(26) Barbatti, M.; Aquino, A. J. A.; Lischka, H. The UV absorption of nucleobases: semi-classical ab initio spectra simulations. Phys. Chem. Chem. Phys. 2010, 12, 4959-4967.

(27) Barbatti, M.; Granucci, G.; Ruckenbauer, M.; Plasser, F.; Crespo-Otero, R.; Pittner, J.; Persico, M.; Lischka, H. NEWTON-X: A package for Newtonian dynamics close to the crossing seam, version 1.4.0; 2013; www.newtonx.org. 
(28) Barbatti, M.; Ruckenbauer, M.; Plasser, F.; Pittner, J.; Granucci, G.; Persico, M.; Lischka, H. Newton-X: a surface-hopping program for nonadiabatic molecular dynamics. Wiley Interdisciplinary Reviews: Computational Molecular Science 2014, 4, 26-33.

(29) Crespo-Otero, R.; Barbatti, M. Spectrum simulation and decomposition with nuclear ensemble: formal derivation and application to benzene, furan and 2-phenylfuran. Theor. Chem. Acc. 2012, 131, 1237.

(30) Arbelo-González, W.; Crespo-Otero, R.; Barbatti, M. Steady and Time-Resolved Photoelectron Spectra Based on Nuclear Ensembles. J. Chem. Theory Comput. 2016, 12, 5037-5049.

(31) Farahani, S.; Frandsen, B. N.; Kjaergaard, H. G.; Lane, J. R. Simulated Electronic Absorption Spectra of Sulfur-Containing Molecules Present in Earth's Atmosphere. J. Phys. Chem. A 2019, 123, 6605-6617.

(32) Murakami, Y.; Onishi, S.; Kobayashi, T.; Fujii, N.; Isshiki, N.; Tsuchiya, K.; Tezaki, A.; Matsui, H. High Temperature Reaction of $S$ $+\mathrm{SO}_{2} \rightarrow \mathrm{SO}+\mathrm{SO}$ : Implication of $\mathrm{S}_{2} \mathrm{O}_{2}$ Intermediate Complex Formation. J. Phys. Chem. A 2003, 107, 10996-11000.

(33) Phillips, L.; Smith, J.; Meyer, B. The ultraviolet spectra of matrix isolated disulfur monoxide and sulfur dioxide. J. Mol. Spectrosc. 1969, 29, 230-243.

(34) Meyer, B.; Stroyer-Hansen, T.; Oommen, T. The visible spectrum of $\mathrm{S}_{3}$ and $\mathrm{S}_{4}$. J. Mol. Spectrosc. 1972, 42, 335-343.

(35) Krasnopolsky, V. $S_{3}$ and $S_{4}$ absorption cross sections in the range of 340 to $600 \mathrm{~nm}$ and evaluation of the $S_{3}$ abundance in the lower atmosphere of Venus. Adv. Space Res. 1987, 7, 25-27.

(36) Billmers, R. I.; Smith, A. L. Ultraviolet-visible absorption spectra of equilibrium sulfur vapor: molar absorptivity spectra of $S_{3}$ and $S_{4}$. J. Phys. Chem. 1991, 95, 4242-4245.

(37) Cobos, C.; Croce, A. Theoretical Study of the Electronic Spectrum of Disulfur Monoxide. Z. Naturforsch., A: Phys. Sci. 2014, 69a, 215-219.

(38) Keller-Rudek, H.; Moortgat, G. K.; Sander, R.; Sörensen, R. The MPI-Mainz UV/VIS Spectral Atlas of Gaseous Molecules of Atmospheric Interest. Earth System Science Data 2013, 5, 365-373.

(39) Molaverdikhani, K.; McGouldrick, K.; Esposito, L. W. The abundance and vertical distribution of the unknown ultraviolet absorber in the venusian atmosphere from analysis of Venus Monitoring Camera images. Icarus 2012, 217, 648-660. Advances in Venus Science.

(40) Zheng, J.; Zhang, S.; Truhlar, D. G. Density Functional Study of Methyl Radical Association Kinetics. J. Phys. Chem. A 2008, 112, 11509-11513.

(41) Bao, J. L.; Zhang, X.; Truhlar, D. G. Barrierless association of $\mathrm{CF}_{2}$ and dissociation of $\mathrm{C}_{2} \mathrm{~F}_{4}$ by variational transition-state theory and system-specific quantum Rice-Ramsperger-Kassel theory. Proc. Natl. Acad. Sci. U. S. A. 2016, 113, 13606-13611.

(42) Zheng, J.; Bao, J. L.; Meana-Paneda, R.; Zhang, S.; Lynch, B. J.; Corchado, J. C.; Chuang, Y.-Y.; Fast, P. L.; Hu, W.-P.; Liu, Y.-P. et al. POLYRATE17; 2017.

(43) Lovas, F. J.; Tiemann, E.; Johnson, D. R. Spectroscopic studies of the $\mathrm{SO}_{2}$ discharge system. II. Microwave spectrum of the $\mathrm{SO}$ dimer. J. Chem. Phys. 1974, 60, 5005-5010.

(44) Tiemann, E.; Hoeft, J.; Lovas, F. J.; Johnson, D. R. Spectroscopic studies of the $\mathrm{SO}_{2}$ discharge system. I. The microwave spectrum and structure of $\mathrm{S}_{2} \mathrm{O}$. J. Chem. Phys. 1974, 60, 5000-5004.

(45) Martin-Drumel, M.; van Wijngaarden, J.; Zingsheim, O.; Lewen, F.; Harding, M.; Schlemmer, S.; Thorwirth, S. Millimeter- and submillimeter-wave spectroscopy of disulfur dioxide, OSSO. J. Mol. Spectrosc. 2015, 307, 33-39.

(46) Werner, H.-J.; Knowles, P. J.; Knizia, G.; Manby, F. R.; Schütz, M.; Celani, P.; Györffy, W.; Kats, D.; Korona, T.; Lindh, R. et al. MOLPRO, version 2012.1, a package of ab initio programs; 2012.

(47) Dunning, T. H.; Peterson, K. A.; Wilson, A. K. Gaussian basis sets for use in correlated molecular calculations. X. The atoms aluminum through argon revisited. J. Chem. Phys. 2001, 114, 92449253.
(48) Dahl, J. P.; Springborg, M. The Morse oscillator in position space, momentum space, and phase space. J. Chem. Phys. 1988, 88, $4535-4547$

(49) Frisch, M. J.; Trucks, G. W.; Schlegel, H. B.; Scuseria, G. E.; Robb, M. A.; Cheeseman, J. R.; Scalmani, G.; Barone, V.; Petersson, G. A.; Nakatsuji, H. et al. Gaussian 9, revision D.01; Gaussian Inc.: Wallingford, CT, 2013.

(50) Stanton, J. F.; Gauss, J.; Cheng, L.; Harding, M. E.; Matthews, D. A.; Szalay, P. G. CFOUR, Coupled-cluster techniques for computational chemistry, a quantum-chemical program package, version 1.0; 2010.

(51) Schneider, W.; Thiel, W. Anharmonic force fields from analytic second derivatives: Method and application to methyl bromide. Chem. Phys. Lett. 1989, 157, 367-373.

(52) Stanton, J. F.; Lopreore, C. L.; Gauss, J. The equilibrium structure and fundamental vibrational frequencies of dioxirane. $J$. Chem. Phys. 1998, 108, 7190-7196.

(53) Stanton, J. F.; Gauss, J. Analytic second derivatives in highorder many-body perturbation and coupled-cluster theories: Computational considerations and applications. Int. Rev. Phys. Chem. 2000, 19, 61-95.

(54) Barone, V. Anharmonic vibrational properties by a fully automated second-order perturbative approach. J. Chem. Phys. 2005, $122,014108$.

(55) Vázquez, J.; Stanton, J. F. Simple(r) algebraic equation for transition moments of fundamental transitions in vibrational secondorder perturbation theory. Mol. Phys. 2006, 104, 377-388.

(56) Yu, Q.; Bowman, J. M. Vibrational second-order perturbation theory (VPT2) using local monomer normal modes. Mol. Phys. 2015, 113, 3964-3971.

(57) Le Sueur, C. R.; Miller, S.; Tennyson, J.; Sutcliffe, B. T. On the use of variational wavefunctions in calculating vibrational band intensities. Mol. Phys. 1992, 76, 1147-1156.

(58) Krasnoshchekov, S. V.; Isayeva, E. V.; Stepanov, N. F. Determination of the Eckart molecule-fixed frame by use of the apparatus of quaternion algebra. J. Chem. Phys. 2014, 140, 154104.

(59) Vogt, E.; Bertran Valls, P.; Kjaergaard, H. G. Accurate Calculations of $\mathrm{OH}$-stretching Intensities with a Reduced Dimensional Local Mode Model Including Eckart Axis Embedding. J. Phys. Chem. A 2020, 124, 932.

(60) Zheng, J.; Bao, J. L.; Zhang, S.; Corchado, J. C.; Meana-Paneda, R.; Chuang, Y.-Y.; Coitino, E. L.; Ellingson, B. A.; Truhlar, D. G. GAUSSRATE, version 17-B; 2017.

(61) Papajak, E.; Zheng, J.; Xu, X.; Leverentz, H. R.; Truhlar, D. G. Perspectives on Basis Sets Beautiful: Seasonal Plantings of Diffuse Basis Functions. J. Chem. Theory Comput. 2011, 7, 3027-3034.

(62) Bass, A. M.; Broida, H. P. Formation and Trapping of Free Radicals; Academic Press: New York, 1960.

(63) Jacox, M. E. Matrix isolation study of the vibrational spectrum and structure of $\mathrm{HC}_{2}$. Chem. Phys. 1975, 7, 424-432.

(64) Wight, C. A.; Ault, B. S.; Andrews, L. On microwave discharge sources of new chemical species for matrix-isolation spectroscopy and the identification of charged species. J. Chem. Phys. 1976, 65, 12441249.

(65) Jacox, M. E.; Thompson, W. E. The vibrational spectra of molecular ions isolated in solid neon. I. $\mathrm{CO}_{2}{ }^{+}$and $\mathrm{CO}_{2}{ }^{-}$. J. Chem. Phys. $1989,91,1410-1416$.

(66) Andrews, L.; Mielke, Z.; Taylor, P. R.; Martin, J. M. L. Matrix Infrared Spectrum and ab Initio Calculations on the PNP Radical. J. Phys. Chem. 1994, 98, 10706-10709.

(67) Jauberteau, J. L.; Jauberteau, I.; Aubreton, J. $\mathrm{NH}_{3}$ and $\mathrm{NH}_{x<3}$ radicals synthesis downstream a microwave discharge sustained in an Ar- $\mathrm{N}_{2}-\mathrm{H}_{2}$ gas mixture. Study of surface reactive processes and determination of rate constants. J. Phys. D: Appl. Phys. 2002, 35, 665674.

(68) Engdahl, A.; Karlström, G.; Nelander, B. The water-hydroxyl radical complex: A matrix isolation study. J. Chem. Phys. 2003, 118, $7797-7802$ 
(69) Krasnopolsky, V.; Parshev, V. A. Chemical composition of the atmosphere of Venus. Nature 1981, 292, 610-613.

(70) Yung, Y. L.; Demore, W. B. Photochemistry of the stratosphere of Venus: Implications for atmospheric evolution. Icarus 1982, 51, 199-247.

(71) Mills, F. P. I. Observations and Photochemical Modeling of the Venus Middle Atmosphere. II. Thermal Infrared Spectroscopy of Europa and Callisto. Ph.D. Thesis, California Institute of Technology, Pasadena, CA, 1998.

(72) Mills, F. P.; Allen, M. A review of selected issues concerning the chemistry in Venus' middle atmosphere. Planet. Space Sci. 2007, 55, $1729-1740$

(73) Zhang, X.; Liang, M. C.; Mills, F. P.; Belyaev, D. A.; Yung, Y. L. Sulfur chemistry in the middle atmosphere of Venus. Icarus 2012, 217, 714-739. Advances in Venus Science.

(74) Krasnopolsky, V. A. A photochemical model for the Venus atmosphere at $47-112 \mathrm{~km}$. Icarus 2012, 218, 230-246.

(75) Heicklen, J.; Kelly, N.; Partymiller, K. The photophysics and photochemistry of $\mathrm{SO}_{2}$. Rev. Chem. Intermed. 1980, 3, 315.

(76) Katagiri, H.; Sako, T.; Hishikawa, A.; Yazaki, T.; Onda, K.; Yamanouchi, K.; Yoshino, K. Experimental and theoretical exploration of photodissociation of $\mathrm{SO}_{2}$ via the $\tilde{\mathrm{C}}^{1} \mathrm{~B}_{2}$ state: identification of the dissociation pathway. J. Mol. Struct. 1997, 413-414, 589-614. Structural Chemistry.

(77) Hu, R.; Seager, S.; Bains, W. Photochemistry in Terrestrial Exoplanet Atmospheres. I. Photochemistry Model and Benchmark Cases. Astrophys. J. 2012, 761, 166.

(78) Rao, T. N.; Collier, S. S.; Calvert, J. G. Primary photophysical processes in the photochemistry of sulfur dioxide at $2875 \AA$. J. Am. Chem. Soc. 1969, 91, 1609-1615.

(79) Otsuka, K.; Calvert, J. G. Decay mechanism of triplet sulfur dioxide molecules formed by intersystem crossing in the flash photolysis of sulfur dioxide (2400-3200 Ang.). J. Am. Chem. Soc. 1971, 93, 2581-2587.

(80) Chung, K.; Calvert, J. G.; Bottenheim, J. W. The photochemistry of sulfur dioxide excited within its first allowed band (3130 $\AA$ ) and the "forbidden" band (3700-4000 ̊̊). Int. J. Chem. Kinet. 1975, 7, 161-182.

(81) Su, F.; Wampler, F. B.; Bottenheim, J. W.; Thorsell, D. L.; Calvert, J. G.; Damon, E. K. On the pressure saturation effect of the quenching of $\mathrm{SO}_{2}\left({ }^{3} \mathrm{~B}_{1}\right)$ molecules. Chem. Phys. Lett. 1977, 51, 150154.

(82) Calvert, J. G.; Su, F.; Bottenheim, J. W.; Strausz, O. P. Mechanism of the homogeneous oxidation of sulfur dioxide in the troposphere. Atmos. Environ. (1967-1989) 1978, 12, 197-226. Proceedings of the International Symposium.

(83) Turco, R. P.; Whitten, R. C.; Toon, O. B. Stratospheric aerosols: Observation and theory. Rev. Geophys. 1982, 20, 233-279.

(84) Whitehill, A. R.; Ono, S. Excitation band dependence of sulfur isotope mass-independent fractionation during photochemistry of sulfur dioxide using broadband light sources. Geochim. Cosmochim. Acta 2012, 94, 238-253.

(85) Kroll, J. A.; Frandsen, B. N.; Kjaergaard, H. G.; Vaida, V. Atmospheric Hydroxyl Radical Source: Reaction of Triplet $\mathrm{SO}_{2}$ and Water. J. Phys. Chem. A 2018, 122, 4465-4469.

(86) Kroll, J. A.; Frandsen, B. N.; Rapf, R. J.; Kjaergaard, H. G.; Vaida, V. Reactivity of Electronically Excited $\mathrm{SO}_{2}$ with Alkanes. J. Phys. Chem. A 2018, 122, 7782-7789.

(87) Krasnopolsky, V. A.; Parshev, V. A. In Venus; Hunten, D. M., Colin, L., Donahue, T. M., Moroz, V. I., Eds.; The University of Arizona Press: Tucson, AZ, 1983.

(88) Krasnopolsky, V.; Parshev, V. A. Photochemistry of Venus' Atmosphere at Altitudes over $50 \mathrm{~km}$ I. Initial Calculations Data. Cosmic Res. 1981, 19, 87-104.

(89) Krasnopolsky, V.; Parshev, V. A. Photochemistry of the Atmosphere of Venus at Altitudes Greater than $50 \mathrm{~km}$ II. Calculations. Cosmic Res. 1981, 19, 261-278.

(90) Krasnopolsky, V. A. Photochemistry of the Atmospheres of Mars and Venus; Springer-Verlag: Heidelberg, Germany, 1983.
(91) Manatt, S. L.; Lane, A. L. A compilation of the absorption cross-sections of $\mathrm{SO}_{2}$ from 106 to $403 \mathrm{~nm}$. J. Quant. Spectrosc. Radiat. Transfer 1993, 50, 267-276.

(92) Sidebottom, H. W.; Badcock, C. C.; Jackson, G. E.; Calvert, J. G.; Reinhardt, G. W.; Damon, E. K. Photooxidation of sulfur dioxide. Environ. Sci. Technol. 1972, 6, 72-79.

(93) Hu, R.; Seager, S.; Bains, W. Photochemistry in Terrestrial Exoplanet Atmospheres. II. $\mathrm{H}_{2} \mathrm{~S}$ and $\mathrm{SO}_{2}$ Photochemistry in Anoxic Atmospheres. Astrophys. J. 2013, 769, 6.

(94) Wilkinson, I.; Boguslavskiy, A. E.; Mikosch, J.; Bertrand, J. B.; Wörner, H. J.; Villeneuve, D. M.; Spanner, M.; Patchkovskii, S.; Stolow, A. Excited state dynamics in $\mathrm{SO}_{2}$. I. Bound state relaxation studied by time-resolved photoelectron-photoion coincidence spectroscopy. J. Chem. Phys. 2014, 140, 204301.

(95) Mai, S.; Marquetand, P.; González, L. Non-adiabatic and intersystem crossing dynamics in $\mathrm{SO}_{2}$. II. The role of triplet states in the bound state dynamics studied by surface-hopping simulations. J. Chem. Phys. 2014, 140, 204302.

(96) Okuda, S.; Rao, T. N.; Slater, D. H.; Calvert, J. G. Identification of the photochemically active species in sulfur dioxide photolysis within the first allowed absorption band. J. Phys. Chem. 1969, 73, $4412-4415$

(97) Jackson, G. E.; Calvert, J. G. Triplet sulfur dioxide-carbon monoxide reaction excited with the $\mathrm{SO}_{2}\left({ }^{1} \mathrm{~A}_{1}\right) \rightarrow \mathrm{SO}_{2}\left({ }^{3} \mathrm{~B}_{1}\right)$ "forbidden" band. J. Am. Chem. Soc. 1971, 93, 2593-2599.

(98) Vandaele, A.; Korablev, O.; Belyaev, D.; Chamberlain, S.; Evdokimova, D.; Encrenaz, T.; Esposito, L.; Jessup, K.; Lefévre, F.; Limaye, S.; et al. Sulfur dioxide in the Venus Atmosphere: II. Spatial and temporal variability. Icarus 2017, 295, 1-15.

(99) Marcq, E.; Mills, F. P.; Parkinson, C. D.; Vandaele, A. C. Composition and Chemistry of the Neutral Atmosphere of Venus. Space Sci. Rev. 2018, 214, 10.

(100) Martins-Costa, M. T. C.; Anglada, J. M.; Francisco, J. S.; RuizLópez, M. F. Photochemistry of $\mathrm{SO}_{2}$ at the Air-Water Interface: A Source of $\mathrm{OH}$ and HOSO Radicals. J. Am. Chem. Soc. 2018, 140, 12341-12344.

(101) Anglada, J. M.; Martins-Costa, M. T. C.; Francisco, J. S.; RuizLópez, M. F. Triplet state promoted reaction of $\mathrm{SO}_{2}$ with $\mathrm{H}_{2} \mathrm{O}$ by competition between proton coupled electron transfer (pcet) and hydrogen atom transfer (hat) processes. Phys. Chem. Chem. Phys. 2019, 21, 9779-9784.

(102) Herron, J. T.; Huie, R. E. Rate Constants at $298 \mathrm{~K}$ for the Reactions $\mathrm{SO}+\mathrm{SO}+\mathrm{M} \rightarrow(\mathrm{SO})_{2}+\mathrm{M}$ and $\mathrm{SO}+(\mathrm{SO})_{2} \rightarrow \mathrm{SO}_{2}+\mathrm{S}_{2} \mathrm{O}$. Chem. Phys. Lett. 1980, 76, 322-324.

(103) Buchachenko, A. L. Recent advances in spin chemistry*. Pure Appl. Chem. 2000, 72, 2243-2258.

(104) Wu, Z.; Wan, H.; Xu, J.; Lu, B.; Lu, Y.; Eckhardt, A. K.; Schreiner, P. R.; Xie, C.; Guo, H.; Zeng, X. The near-UV absorber OSSO and its isomers. Chem. Commun. 2018, 54, 4517-4520.

(105) Ramírez-Solís, A.; Jolibois, F.; Maron, L. Born-Oppenheimer DFT molecular dynamics studies of $\mathrm{S}_{2} \mathrm{O}_{2}$ : Non-harmonic effects on the lowest energy isomers. Chem. Phys. Lett. 2011, 510, 21-26.

(106) Hopkins, A. G.; Daly, F. P.; Brown, C. W. Infrared spectra of matrix isolated disulfur monoxide isotopes. J. Phys. Chem. 1975, 79, 1849-1851.

(107) Salama, F.; Frei, H. Near-infrared-light-induced reaction of singlet sulfur monoxide with allene and dimethylacetylene in a rare gas matrix: infrared spectra of two novel episulfoxides. J. Phys. Chem. 1989, 93, 1285-1292.

(108) Nxumalo, L.; Ford, T. The sulphur dioxide dimer. A matrix isolation infrared spectroscopic study. J. Mol. Struct. 1995, 347, 495507. Molecular Spectroscopy and Molecular Structure 1994.

(109) Ito, F.; Hirabayashi, S. Infrared spectroscopy of $\mathrm{SO}_{2}$ clusters in rare gas matrices revisited: Assignment of species in Ar matrix. Chem. Phys. 2009, 358, 209-218.

(110) Hopkins, A. G.; Brown, C. W. Infrared spectrum of sulfur monoxide. J. Chem. Phys. 1975, 62, 2511-2512. 
(111) Pehkonen, S.; Lundell, J.; Khriachtchev, L.; Pettersson, M.; Räsänen, M. Matrix isolation and quantum chemical studies on the $\mathrm{H}_{2} \mathrm{O}_{2}-\mathrm{SO}_{2}$ complex. Phys. Chem. Chem. Phys. 2004, 6, 4607-4613.

(112) Yung, Y. L.; Liang, M. C.; Jiang, X.; Shia, R. L.; Lee, C.; Bézard, B.; Marcq, E. Evidence for carbonyl sulfide (OCS) conversion to CO in the lower atmosphere of Venus. J. Geophys. Res. 2009, 114. DOI: 10.1029/2008JE003094.

(113) Mills, F. P. I. Observations and Photochemical Modeling of the Venus Middle Atmosphere. II. Thermal Infrared Spectroscopy of Europa and Callisto. Ph.D. Thesis, California Institute of Technology, Pasadena, CA, 1998; Appendix B, pp 5-14.

(114) Jones, A. V. Infra-Red and Ultraviolet Spectra of Sulphur Monoxide. J. Chem. Phys. 1950, 18, 1263-1268. Misassgined SO to the spectrum. The spectrum matches $\mathrm{S}_{2} \mathrm{O}$.

(115) Miliordos, E.; Xantheas, S. S. On the Bonding Nature of Ozone $\left(\mathrm{O}_{3}\right)$ and Its Sulfur-Substituted Analogues $\mathrm{SO}_{2}, \mathrm{OS}_{2}$, and $\mathrm{S}_{3}$ : Correlation between Their Biradical Character and Molecular Properties. J. Am. Chem. Soc. 2014, 136, 2808-2817.

(116) Lyons, J. R. An estimate of the equilibrium speciation of sulfur vapor over solid sulfur and implications for planetary atmospheres. $J$. Sulfur Chem. 2008, 29, 269-279.

(117) Grosch, H.; Fateev, A.; Clausen, S. UV absorption crosssections of selected sulfur-containing compounds at temperatures up to $500^{\circ}$ C. J. Quant. Spectrosc. Radiat. Transfer 2015, 154, 28-34. 